\title{
Standardising Marine Renewable Energy Testing: Gap Analysis and Recommendations for Development of Standards
}

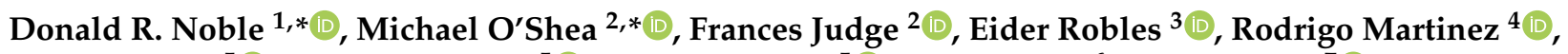

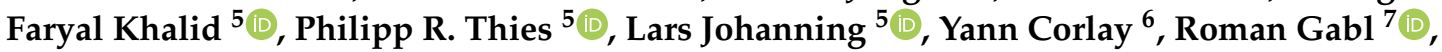 \\ Thomas A. D. Davey ${ }^{7}$, Nithiananthan Vejayan ${ }^{6}$ and Jimmy Murphy ${ }^{2}{ }^{10}$
}

1 Institute for Energy Systems, School of Engineering, The University of Edinburgh, Edinburgh EH9 3FB, UK

2 MaREI Centre, Environmental Research Institute, University College Cork, P43 C573 Co. Cork, Ireland; frances.judge@ucc.ie (F.J.); Jimmy.murphy@ucc.ie (J.M.)

3 TECNALIA, Basque Research and Technology Alliance (BRTA), Parque Tecnológico de Bizkaia, Astondoa Bidea, Edificio 700, E-48160 Derio, Spain; eider.robles@tecnalia.com

4 ESRU, Department of Mechanical \& Aerospace Engineering, University of Strathclyde, James Weir Building, Montrose Street, Glasgow G1 1XJ, UK; r.martinez@strath.ac.uk

5 College of Engineering, Mathematics and Physical Sciences, University of Exeter, Treliever Road, Cornwall TR10 9FE, UK; f.khalid2@exeter.ac.uk (F.K.); P.R.Thies@exeter.ac.uk (P.R.T.); L.Johanning@exeter.ac.uk (L.J.)

6 European Marine Energy Centre, The Charles Clouston Building, ORIC, Back Road, Orkney KW16 3AW, UK; Yann.Corlay@emec.org.uk (Y.C.); Nithiananthan.Vejayan@emec.org.uk (N.V.)

7 Institute for Energy Systems, School of Engineering, FloWave Ocean Energy Research Facility, The University of Edinburgh, Max Born Crescent, Edinburgh EH9 3BF, UK; Roman.Gabl@ed.ac.uk (R.G.); Tom.Davey@flowave.ed.ac.uk (T.A.D.D.)

Citation: Noble, D.R.; O'Shea, M.; Judge, F.; Robles, E.; Martinez, R.; Khalid, F.; Thies, P.R.; Johanning, L.; Corlay, Y.; Gabl, R.; et al. Standardising Marine Renewable Energy Testing: Gap Analysis and Recommendations for Development of Standards. J. Mar. Sci. Eng. 2021, 9 , 971. https://doi.org/10.3390/ jmse9090971

Academic Editors: Eugen Rusu and Rafael J. Bergillos

Received: 7 July 2021

Accepted: 29 August 2021

Published: 6 September 2021

Publisher's Note: MDPI stays neutral with regard to jurisdictional claims in published maps and institutional affiliations.

Copyright: () 2021 by the authors. Licensee MDPI, Basel, Switzerland. This article is an open access article distributed under the terms and conditions of the Creative Commons Attribution (CC BY) license (https:// creativecommons.org/licenses/by/ $4.0 /)$.

* Correspondence: D.Noble@ed.ac.uk (D.R.N.); michaeloshea@ucc.ie (M.O.)

Abstract: Marine renewable energy (MRE) is still an emerging technology. As such, there is still a lack of mature standards and guidance for the development and testing of these devices. The sector covers a wide range of disciplines, so there is a need for more comprehensive guidance to cover these. This paper builds on a study undertaken in the MaRINET2 project to summarise recommendations and guidance for testing MRE devices and components, by reviewing the recently published guidance. Perceived gaps in the guidance are then discussed, expanding on the previous study. Results from an industry survey are also used to help quantify and validate these gaps. The main themes identified can be summarised as: the development progression from concept to commercialisation, including more complex environmental conditions in testing, accurately modelling and quantifying the power generated, including grid integration, plus modelling and testing of novel moorings and foundation solutions. A pathway to a standardised approach to MRE testing is presented, building on recommendations learnt from the MaRINET2 round-robin testing, showing how these recommendations are being incorporated into the guidance and ultimately feeding into the development of international standards for the marine renewable energy sector.

Keywords: gap analysis; guidance; standards; marine renewable energy; tank testing; round-robin

\section{Introduction}

Marine renewable energy (MRE) is emerging technology. As such, there is still a lack of mature standards and guidance for the development and testing of these devices. This paper aims to briefly summarise the relevant types of published guidance and highlight any gaps or areas for further development. This covers guidance for testing wave, tidal, and offshore wind energy technologies and components for the full range of technology readiness levels (TRL). It does not specifically address the development and testing of a plant's balance including offshore substations, subsea cables, etc.

A gap analysis was undertaken as part of the MaRINET2 project in 2017/2018 to identify areas that are not well covered by existing documents [1]. This paper updates 
that gap in the analysis with recently published guidance and results from a survey of device developers and MaRINET2 test infrastructure managers. The MaRINET2 project comprises 53 facilities across Europe that test marine energy devices, including test tanks (flumes, towing tanks, wave basins), wind tunnels, field test sites, component test facilities, and other cross-cutting research facilities. Through the project's Transnational Access (TNA) programme, a total of 173 test campaigns have been funded to date, equating to over 610 weeks of access to these facilities. Additionally, a programme of round robin testing within the MaRINET2 project aims to identify the effects that individual laboratory facilities have on performance results for a particular device model.

The rest of this paper is structured as follows. Context on the complexity of the MRE sector is given in Section 1.1, followed by a summary of the structure development process, usually given Section 1.2. The relevant literature is reviewed in Section 2, including other studies of MRE guidance gaps and an overview of the available guidance. Section 3 outlines the methodology of this study. The identified gaps are discussed in Section 4, with the results of the survey prioritising those presented in Section 5. A discussion of a future pathway to a standardised approach to MRE testing is offered in Section 6, followed by conclusions in Section 7 and a tabulated summary of the topics covered by published MRE testing guidance documents in the Appendix A.

\subsection{Complexity of the MRE Sector}

Marine renewable energy is a complex and multi-faceted sector, covering a wide range of topics. Those working in the sector also have a wide range of experience and technical backgrounds.

Testing prototype devices and components at a reduced scale is a well-established practice. It is cost-effective, and allows for the use of controlable and repeatable test environments. The reduced scale can, however, introduce unwanted scaling effects, and the processes involved may have conflicting requirements (e.g., Froude/Reynolds scaling mismatch). This leads to a need to scale the dominant physical process(es) and compensate or reduce the error in others.

Although all were designed to harness renewable energy and operate in the harsh marine environment, the MRE technologies of wind, wave, and tidal-stream are quite different. For wave energy in particular, there is a lack of design consensus, with many radically differing device topologies being considered to harness power from the waves. This diversity of concepts complicates the process of producing development and testing guidance.

The marine environment in which these devices operate and harness energy from is highly complex, with a range of interlinking processes. Waves of various frequencies propagate in a different directions, interacting with each other as well as with turbulent tidal currents, coastal bathymetry, and the wind blowing over the surface. It also contains marine life that can interact with, and grow on, devices. This can have a significant influence and be difficult to model. In early-stage development, it is important to simplify the environmental conditions where possible to aid understanding of the overall device performance. More realism and accuracy can be added to the testing as the technology progresses.

MRE testing guidance is, therefore, required to cover a wide range of topics. These include how to characterise and represent the marine environment, how this interacts with the renewable energy device concept, how to measure and simulate the conditions for component and scale model testing, etc. Designing an electro-mechanical machine to harness power from the marine environment is very much a multi-disciplinary endeavour, involving fluid dynamics, electrical and control systems, materials engineering, and much more. On top of this, the needs of the dissimilar audiences of technology developers and test facilities need to be considered when producing guidance. 


\subsection{Structured Development Plans}

A structured approach to development is common for most devices, following an incremental staged approach from concept to commercialisation, with increasing complexity and cost. The stages can broadly be defined per Table 1, which aligns with IEC guidelines for early-stage development and recently published work by the IEA-OES [2]. Prototypes are usually first tested with small simplified models in smaller university laboratories or similar facilities. As the technology is developed, both model scale and complexity increase, as does the corresponding cost and time required. Overlap between stages may be likely. Development is often an iterative process, particularly for subsequent revisions to the device concept. For example, returning to the wave basin to test a refined design following an open-water deployment. Alongside physical model testing, significant effort will be spent on numerical modelling, although this is outside the scope of this study. Developers should not only focus on increasing TRL; they also need to consider the commercial proposition they are producing. Both the commercial readiness index [3] and technology performance levels [4] can assist with this. In general, the guidance that does exist on development progression may not be sufficiently broad in scope and/or detail, and development progression is still seen as a gap by many, as shown by the responses to the survey in Section 5 .

Table 1. Five stages of development, for marine renewable energy devices. After [2,5-8].

\begin{tabular}{lcll}
\hline Stage & TRL & Nominal Test Scale * & Typical Infrastructure \\
\hline 1. Concept development & $1-3$ & Small scale (circa 1:50) & Small university laboratory \\
2. Design optimisation & $3-5$ & Larger scale (circa 1:25-1:10) & Industrial scale laboratory \\
3. Scaled demonstration & $5-6$ & Sub-prototype size (circa 1:4) & Benign test site \\
4. Commercial-scale single device demonstration & $7-8$ & Approaching full size (circa 1:1) & Exposed test site \\
5. Commercial-scale array demonstration & 9 & Full size, small arrays & Commercial site \\
\hline
\end{tabular}

* Scales refer to WEC and TST models; smaller scales are typically used at each stage for FOWT, given the larger size of the prototypes.

\section{Literature Review}

\subsection{Previous MRE Guidance Gap Identification Studies}

As noted above, a gap analysis was conducted in $2017 / 2018$ as part of the MaRINET2 project [1]. This was based on a review of published documents, responses to a questionnaire sent out to each test facility involved in the MaRINET2 programme, and the experience of project partners contributing to the report. Key gaps in guidance have been highlighted, including:

- Modelling the power take-off (PTO) subsystem, including scaling, simulation at model scale, and performance prediction/assessment.

- Moorings and cable systems.

- Working towards a coherent set of guidelines/standards used by all test facilities.

- $\quad$ Testing in combined wave-current conditions.

- An understanding of failure mechanisms resulting from corrosion, and of the effect of wear, corrosion and fatigue combinations.

Importantly, it found that, despite documents covering a variety of technical aspects, there is a lack of guidance on how to transition between stages, and deal with scaling from a controlled laboratory setting to the uncontrolled, hostile, ocean environment. These identified gaps have been expanded on in this paper, and the recent work to address them has been reviewed.

In 2017, the US National Renewable Energy Laboratory (NREL) ran a workshop focused on the instrumentation aspects of MRE technology development [9]. This workshop brought experts in marine energy measurement, testing, and technology development together to both present and discuss the instrumentation and data-processing needs of the marine energy industry. The aims were to try understand the current state of the art, 
identify any gaps, and define pathways to resolve these. Four themes emerged from this work, which are still relevant today:

1. Limited knowledge transfer. It needs to be easier to find the wealth of experience, tools, and know-how that have been developed by the sector, in order for the industry to avoid repeating mistakes, minimise duplicate efforts, and leverage the experience of others to accelerate development.

2. High cost of measurement. This can lead to a trade-off between the breadth and duration of a test, and the number and quality of measurements.

3. Better measurement capabilities at low TRL. To facilitate scale model testing at 1:10 or smaller. Measurement capabilities are often inadequate and sensors either do not exist, are too expensive, or adversely impact device response.

4. Open-source tools for unified data processing and analysis. At present, data processing and analysis is conducted on a project-by-project basis using custom code. The sharing of vetted data reduction, processing, QA, and visualisation code, and adoption of standard methods would allow the industry to accelerate the analysis, and would increase the credibility of test results.

Prior to this, in 2014, the ORE Catapult and EMEC held a workshop to review the standards and guidelines for wave and tidal energy and to identify gaps [10]. In advance of this workshop, four topic areas were identified, namely, offshore installation, operation and maintenance $(\mathrm{O} \& \mathrm{M})$, subsea cable lifecycle, and environmental monitoring. In addition to this, another four topics were raised at the workshop: data sensing and communication, mechanical design in shallow water environments, vessels and equipment used in marine renewable energy development, and subsea connectors. A key recommendation from this was close collaboration with the IEC to develop standards, which has happened through the Technical Committee (TC) 114 [11].

\subsection{Types of Guidance Available for MRE Development}

There is a broad range of standards and guidance documents available for the development and testing of MRE technologies. For reasons of brevity, it is not possible to summarise all of the relevant documents used across the wide-ranging MRE sector. The complexity of the sector is discussed further in Section 1.1.

Standards and guidance are quite general terms and may apply to a range of topics, including published standards, technical specifications, guidance protocols, best practice, or recommendations from industry. The types of guidance available for device developers and test facilities can be broadly categorised into four groups:

\section{General Standards}

Published by standards bodies such as the International Standards Organisation (ISO) or the International Electrotechnical Commission (IEC); these cover topics that are generally applicable to a wide range of established sectors. Examples include: ISO 9001 Quality management, or ISO/IEC 17025 General requirements for the competence of testing and calibration laboratories. These are beyond the scope of this paper.

Technically focused and/or sector-specific Standards, Technical Specifications (TS), and Recommended Procedures (RP)

Published by standards bodies or by certification organisations like DNV, these focus on technical aspects more relevant to the MRE and related sectors. Examples include: IEC 61400 Wind turbines, IEC TS 62600 wave, tidal and other water current converters, and DNV-OS-J103 Design of Floating Wind Turbine Structures.

\section{Sector-specific guidance documents}

Developed by projects or organisations, these focus more specifically on aspects of MRE development and testing. Examples include: Protocols for the Equitable Assessment of Marine Energy Converters (EquiMar) [12] and supporting project deliverables, the MaRINET and MaRINET2 project deliverables, and the set of rec- 
ommended procedures and guidelines published by the International Towing Tank Conference (ITTC) [13]. A tabular summary of the key topics covered by 78 of these documents is provided in Appendix A.

\section{Other Sources}

In addition, valuable information may be contained within internal guidance/reference documents, and specific details are often included in published academic papers and other reports. These may then be assimilated into the broader publications from the ITTC or IEC, etc.

While the use of standards developed by other, similar sectors may be considered where MRE specific standards are lacking, IEC TS 62600-2 includes a specific caveat regarding the suitability and/or relevance of non-marine-renewable-energy-specific standards, and recommends a formal assessment of risks before these are used. "The use of a standard from other mature industries where nothing explicitly written for MECs [marine energy converters] is available carries a risk that important considerations for the marine energy application are given insufficient emphasis or ignored completely. This applies to standards written for offshore wind, oil and gas, and shipping." [14].

\subsection{Recent and Upcoming Guidance for MRE Development}

The MaRINET2 project has produced draft guidelines for testing ORE devices for both the laboratory personnel undertaking the testing and technology developers. These guidelines will be updated at the end of the project (Q4 2021) using feedback from both groups [15,16]. Additionally, a standardised test verification process has been outlined [17] This will allow third parties to independently verify that tests conducted in MaRINET2 facilities and elsewhere have been carried out in a scientific and logical way, to ensure robustness of the results. Two published project reports cover electrical subsystems and grid integration. The first proposes a framework for remote access to infrastructure and presents a case study of access to a PTO test lab [18]. The second proposes approaches to testing the grid connection of ORE, both at present and in the future [19].

The upcoming MaRINET2 deliverable D4.3 Standard Testing Procedures [20] is a set of guidelines based on the MaRINET2 Round Robin (RR) tests of wave, tidal, offshore wind, electrical components and cross-cutting technologies. These guidelines, compared to currently available standard procedures and guidelines, give a more practical and quantitative approach based on the lessons learnt during the RR testing.

In the past three years, the IEC Technical Committee TC114 has published six relevant parts of TS 62600 Marine energy—wave, tidal and other water current converters-as summarised below.

- Part 1:2020 Vocabulary [21] gives an updated terminology for the series.

- Part 2:2019 Marine energy systems—design requirements [14] has also been updated with design conditions unique to marine energy converters.

- Part 3:2019 Measurement of mechanical loads [22] covers this for the purpose of load simulation, model validation, and certification. It also includes guidance on full-scale testing.

- Part 4:2020 Specification for establishing the qualification of new technology [23] has updated the qualification of development.

- Part 30:2018 Electrical power quality requirements [24] covers the definition and specification of the quantities to be determined to characterise the power quality of an MEC and measurement procedures to quantify the characteristics of an MEC.

- Part 103:2018 Guidelines for the early-stage development of wave energy convertersbest practices and recommended procedures for the testing of pre-prototype devices [25] describes the minimum model test programmes that form the basis of structured technology development.

Further parts and updates are due to be published in the coming years, including Part 202 Scale testing of tidal stream energy systems. The MET-CERTIFIED project (2016-2019) 
aimed to increase the insurability of tidal energy projects through the development of international standards, including parts 2, 30, 200, 201 and 202 of IEC TS 62600 [26].

The LIFES50+ project focused on developing floating offshore wind turbine (FOWT) substructures for water depths of $50 \mathrm{~m}$ or more. Two of the project deliverables are particularly relevant. Firstly, a review of FOWT guidelines and design practice [27], comparing the draft of IEC TS 61400-3-2 [28] and guidance from the classification societies DNV, ABS and Class NK. Secondly, guidance and recommended methods for hybrid/hardware-in-theloop-based FOWT experimental testing [29] summarising hydrodynamic and aerodynamic testing of FOWT, plus hardware-in-the-loop or real-time hybrid model testing in both wave tanks and wind tunnels.

The IEA-OES recently published a detailed evaluation and guidance framework for ocean energy technologies, resulting from the ongoing 'Task 12' activities [2]. This captures the technology development stages discussed in Section 1.2. The IEA-OES add a Stage 0 for concept creation and very early evaluation. The framework sets out nine evaluation areas with corresponding evaluation criteria and recommended activities to complete in each stage of development. The evaluation areas are: power capture, power conversion, controllability, reliability, survivability, maintainability, installability, manufacturability, and affordability. The overall affordability can be seen as an overarching area, as all other areas impact this, and it drives the likelihood of a project or technology succeeding. While this report identifies a wide range of evaluation criteria (or metrics/key performance indicators), it does not set thresholds to indicate success at each stage-noting that these are specific to technologies, projects, markets, and investors; therefore, a standard value cannot be defined.

The ITTC recommended procedures and guidelines were last updated in 2017, following the 28th Conference in Wuxi, China. The 29th Conference will be held virtually in June 2021. Topics for discussion include the modelling of environmental conditions [30] and an update on hydrodynamic modelling of marine renewable energy devices [31].

\section{Materials and Methods}

A gap analysis was undertaken as part of the MaRINET2 project in 2017/2018 to identify areas that are not well covered by existing documents [1]. This paper updates that gap analysis, building on the knowledge of the partners within the MaRINET2 consortium.

To offer a wider perspective than just the authors', a short survey was conducted to review and prioritise the identified gaps, and offer scope for participants to flag any missing gaps. An email request to complete a one-page questionnaire was circulated to a list of relevant contacts who are involved with device testing. This included facility managers within the MaRINET2 project, plus technology developers that had participated in either the MaRINET2 TNA testing, the Wave Energy Scotland programmes ${ }^{1}$, or the TEAMER program ${ }^{2}$ in the USA.

Participants in the questionnaire were asked to rank each of the 26 gaps identified by the authors using a four-point Likert scale of: not a significant gap, slightly significant gap, somewhat significant gap, or very significant gap. All questions included the option of don't know/no answer. A free text input box was also provided at the end, where the respondents were prompted to add in other gaps, reasoning behind their ranking choices, or any other comments.

Minimal details were collected to categorise respondents into infrastructure managers, technology developers, or other, and in which programmes they had participated. The developers were also asked what type of technology(s) they were developing and the approximate TRL of the device/concept. Respondents were also asked to provide the name of their facility or technology to assist interpretation of results, but were advised that their responses would be aggregated and not individually attributable. No other questions were asked. Participation in the survey was voluntary and all questions were optional. The survey was open for responses throughout March and April 2021. 


\section{Analysis of Gaps in Published Guidance}

This section presents the gaps that have been identified in the guidance for testing MRE devices. For each, a short description of the gap and why it is important is presented, together with reference to the guidance that does exist. It includes comments received in the survey in addition to the authors' views. The gaps identified first cover specific subsystems and cross-cutting themes, then cover more general topics.

Beyond guidance, there may also be a wider range of other gaps and barriers in the development of the MRE sector. This is beyond the scope of this paper, but broad challenges in the sector are covered in the Strategic Research and Innovation Agenda (SRIA) for Ocean Energy [32]. The SRIA focuses on the development of technology rather than the guidance and, eventually, standards to facilitate widespread adoption; however, the last of the 17 identified challenges is 'standardisation and certification'.

\subsection{Development Progression}

While existing guidance covers the development progression from concept to commercialisation, this can still be considered a gap, as reflected in the findings from the survey (Section 5). The areas of concern include how to scale up tests from controlled to uncontrolled environments and, similarly, progression from the laboratory to the sea. More detail is perhaps needed on what should be tested at each stage of development, and facilities for doing so. Similarly, what is required to progress from one stage-gate to the next may need more detail. One developer commented that existing guidance tends to focus on TRL steps (or the stages outlined in Table 1) rather than on an evaluation of commercial viability at an early stage. Another developer highlighted the lack of metrics used to inform the progression from small- to large-scale tank testing, then to part- and full-scale sea-trials.

As mentioned in Section 2.3, recent work by the IEA 'Task 12' group has developed a standardised set of metrics to quantify technology development [2]. It is noted, however, that no thresholds have been set for these metrics to allow developers to track whether they are on the correct pathway to a successful commercial product. Given the diversity of the sector, with vastly differing concepts and scales, setting metric thresholds is an extremely difficult task. Different combinations of cost, performance, reliability, etc., could all potentially lead to a successful concept.

While a decade old and focusing only on WECs, the IEA-OES Guidelines for the development and testing of wave energy systems [8] present a comprehensive development progression framework. This has been summarised and updated in more recent publications, including the IEC TS on early-stage testing of WECs [25] and scale testing of tidal energy systems [33].

\subsection{More Realistic Environmental Conditions}

Three of the facility managers surveyed specifically highlighted the difficulty in reproducing complex sea states for model scale testing, noting the impact on other factors. Realistic environmental conditions were also rated as either somewhat or very significant by the majority of facility managers.

\subsubsection{Combination of Site Conditions}

Most existing guidance on specifying environmental conditions covers simplified conditions, such as uni-directional waves, that are fundamental in understanding device performance at a basic level. However, the real marine environment is much more complex, with multi-directional waves combined with turbulent tidal currents. Understanding how devices will behave and survive in this complex environment requires the measurement, characterisation, specification, creation, validation, and modelling of these conditions together [34]. This joined-up approach between site characterisation and testing was also flagged as key by a facility manager. Another point raised was that simple $H_{s}, T_{p}$ spectra (possibly with a spreading function) is only really useful for early-stage testing, even 
though this is recommended in much of the existing guidance. Site-specific non-parametric spectra (such as that detailed in [35]), directional spreading, and the use of multi-modal sea states for testing all need to be considered. Another facility manager raised the potential importance of infragravity waves and their impact on structures installed in shallow water as a gap that is not covered in the existing guidance. Guidance is needed on how to characterise these, whether from on-site measurement or numerical models.

There is limited guidance on combined waves and currents, both specifying conditions at sites, and relating to tank testing MECs. Deliverable D2.2 from Equimar [36] provides guidelines on modelling wave-current interaction, but also details the limitations inherent to this field. As pointed out above, there are few guidelines in the existing documentation on methods to reach a sufficiently realistic representation of this phenomenon. Existing methods use simplified models for representing wave and tides, which may not be representative of the constraints the MECs might experience on site. This lack of guidance on combined conditions was highlighted as an issue in Noble et al. [5]. The interaction of waves at oblique angles to currents also has limited guidance, which might result from the fewer facilities that are able to produce these conditions.

Modelling of the site conditions have become a solution to creating a realistic representation of the test environment. However, even if the results of the simulations have been covered in several reports, there are few explanations on how they could be directly used for power performance assessment site characterisation, as explained in Equimar D2.3 [37]. The impact of even a moderate tidal current on the available wave shape and power is explored further in Draycott et al. [38], Pillai et al. [39]. While not addressed in any guidance to date, it will be of critical importance for floating devices, in particular, WECs aiming to harness the varying power and floating TECs. This point was specifically highlighted as a gap by a facility manager. In general, IEC technical specifications 62600-101, 102, 201 [40-42] regarding site and resource characterisation for both wave and tidal devices do not provide guidance on how wave-current interactions should be considered for resource assessment.

\subsubsection{Impact of Marine Environment on MEC Integrity}

The items covered in industry documentation regarding the survivability of the devices remain general and do not provide clear requirements on what should be considered in the design phase. The main recommendations are inherited from more mature fields of marine industry but do not cover all aspects purely specific to the field of marine energies. IEC TS 62600-2 [14] provides, for example, a clear set of references and example of the methods used in the oil and gas industry, but few case studies exist regarding assessment of MRE device survivability.

The specific items such as the PTO interactions are mentioned and generally covered in the documents, but a more in-depth assessment could help to generalise the design phase process.

In addition, limited guidance exists in the industry standards regarding the consideration of biofouling on MEC structure and moorings. IEC TS 62600-10 [43] and 62600-2 [14] provide information considering this aspect during the design phase of the machines, but, once again, are dedicated to other sectors. The impact of fouling on motions of the MECs sub-components plays a significant role in their performance. Fouling will increase the drag and weight of the mooring lines near the water surface. Marine growth can also be a significant issue for the integrity of the device and moorings, for example biocorrosion of metal components or degradation of ropes. Protective coating for metallic components are available, as well as protective covers for mooring lines to prevent the ingress of marine growth into the line. Specific methods to quantify the expected growth at the design stage and limit biofouling on the main structural components would be useful.

The guidelines for assessing the effects of the marine environment on the structural integrity of MECs remain, in general, high-level. The wide range of studies and standards produced for other sectors of marine industry are useful and can be applied to some extent. 
However, some items specific to the challenges of MRE device survivability may need to be addressed in more detail.

\subsection{PTO and Control}

Although power take-off (PTO) and control are very frequently grouped, one surveyed device developer suggested it may be a mistake to conflate the two, as these are separate issues with entirely different levels of uncertainty. Another developer indicated that guidance for the scaled testing of WECs with pneumatic/compressible PTOs is lacking. The existing guidance also does not chart a path for the progression of such WECs through the TRL scale.

Guidance exists for PTO and control systems, as detailed in MaRINET2 D2.1 (Sections 4.2.1.2 and 5.2.1.2) [1]. However, one of the most prevalent themes for additional standards was related to the PTO subsystem, and was consistently raised in relation to both wave and tidal energy converters. It was highlighted that there is a desire for guidance surrounding the effective scaling and simulation of PTO at model scale, along with methods for performance assessment. A facility manager responded with this point, noting that, while there is some guidance for modelling the PTO measuring, the performance is still difficult.

Additionally, it has been noted that there is a gap in terms of the available physical infrastructure to test the wide range of PTO types for each technology. The test benches that do exist have their own physical properties and constraints, and it is difficult to obtain analogous testing between PTO types. Therefore, for early development stage testing campaigns, there is a lack of standardised guidance on building a mechanism representative of the power take-off (power conversion chain similitude) and assessing their performances. More detailed methods for PTO performance assessment would, therefore, be useful for the sector.

\subsection{Grid/electrical}

There is a twofold gap in grid connected marine energy converters: no exclusive standard of test methodologies exist, and there is a lack of dedicated grid connection normative. Due to the lower technological maturity of wave and tidal energy systems, very few studies or scientific papers have focused on their grid connection to date. In addition, most of the grid integration studies addressing ocean energy technologies still consider energy farms of limited capacity, which are mainly connected to distribution networks [44]. It is clear that offshore renewable farms will, in the long run, be in the range of hundreds of MW of installed power. This implies a direct connection to the transmission system, as with most offshore wind energy farms.

As a follow up of Endegnanew et al. [45], the work in Robles et al. [46] summarises the main critical aspects related to the grid connection of marine energy farms, while reviewing basic concepts and control requirements that represent the cornerstones of the grid integration of marine farms. It also highlights that the requirements for the grid connection are normally influenced by local regulations, and ascertains that grid codes differ from country to country. In addition, most of the connection requirements only consider wind farms, with no explicit mention to wave or tidal, which constitutes a regulatory gap.

Although the European Network of Transmission System Operators for Electricity (ENTSO-E) works within a Grid Code for grid interconnection requirements for all generators, it only sets ranges of limit values without specific figures, leaving several conditions to be established by each of the national transmission/distribution system operators.

Regarding guidance in testing, there is an international standard of power quality assessment for grid-connected wind turbines IEC 61400-21 [47]. Based on this, the IEC TC114 issued IEC TS 62600-30 Electrical power quality requirements for wave, tidal and other water current energy devices in 2018 [24]. However, this only gives general rules 
about the power quality and test procedures, without clear directions on the compliance of the facility with these quality criteria.

\subsection{Moorings, Foundations, and Mounting Solutions}

The risk associated with mooring line failure and costly remote-data-monitoring equipment leads to over-engineered mooring system designs that have been identified as a key cost driver for MRE [48,49]. To increase confidence in the peak load design of the mooring system, it is important to analyse the dynamic response of the MRE components and system in a controlled environment through physical testing. A standardised approach to mooring system testing has not been formalised for MEC devices internationally, partly due to the lack of convergence to a design solution and insufficient field deployment experience. Existing practices involve a combination of physical testing of individual components, wave tank testing of scaled models of complete systems, and field-testing of prototypes at nursery test sites.

Component testing activities, including the testing of established and novel components, are primarily governed by available general guidance based on the fabrication material to determine parameters such as the stiffness and break strength. However, this guidance is usually drafted to target other applications; therefore, it does not include dynamic testing for the high-frequency cyclic loads that are relevant to MRE devices. For performance characterisation of novel components, guidance from generic application is tailored at the discretion of the developers to meet industry-specific requirements. As more innovative components are introduced, there is an increase in the need for an industry-specific component test guidance.

Tank tests of scaled MRE devices are designed to validate analytical concepts. For WECs, the focus of most tank tests lies in the PTO and the model is designed to ensure independent characterisation of the PTO performance through a simplistic mooring representation. However, to fully characterise WEC performance, it is advisable that the coupled performance of the mooring system and PTO should be assessed. Additionally, the accurate scaling of tank models to field deployment is limited by the wave tank depth and the limited material properties of off-the-shelf mooring components.

Marine growth effects, which will be encountered in the field, are generally challenging to model in the tank, but can be incorporated through estimated additional drag and weight at smaller scale. These are not standardised, but have been trialled and quantified for numerical design [50].

The IEC standard [11] for moorings defines consequence classes based on safety factors from the least critical classes in oil and gas standards. Better calibration of these safety factors can be done with an increase in installation and operational experience. To address the high risk of novel components, higher safety factors are introduced and existing guidance does not provide the opportunity for a rigid certification process to bypass this requirement. Existing field-testing [51] has shown that there should be due consideration of the design of the condition-monitoring system for the moorings. It should not compromise the integrity of the mooring design and should be resistant to corrosion and biofouling to prevent loss of data.

As part of the survey, one facility manager suggested this is not a significant gap, as this is covered in existing oil \& gas industry standards, although the 7 noted that there are some considerations specific to MRE.

\subsection{Other Gaps in Guidance}

Other technology-specific gaps and broad-ranging gaps have been identified within the published guidance, as discussed below.

\subsubsection{Impact of Blockage on Tidal Turbine Tests}

The blockage effect is when the upstream flow is forced through the rotor due to the rotor partially obstructing the tank's cross-section. In response, performance and 
thrust coefficients $\left(C_{P}\right.$ and $C_{T}$, respectively) can be perceived as higher than they are in reality. $C_{P}$ can sometimes exceed the maximum theoretical value known as the Betz limit. Blockage is measured as the ratio between the rotor area and the cross-sectional area of the tank. The round robin testing undertaken during MaRINET and MaRINET2 and reported in Gaurier et al. [52,53], showed that testing small-scale tidal turbine prototypes in a facility producing blockage ratios as low as $5 \%$ may still influence the performance of turbine. In addition, although Gaurier et al. [52,53] used the blockage correction method developed by Bahaj et al. [54], specific blockage correction technique(s) have not been established/standardised to date.

\subsubsection{Flow Characterisation Techniques}

To date, there is no guidance on how to characterise the flow a tidal turbine will be subjected to during laboratory testing. However, Gaurier et al. [53] propose a rotor-area flow mapping for a more accurate representation of the flow: disc-integrated velocity average (DIVA) method. In said work, they propose five-point measurements on the vertical and on the horizontal planes of the rotor. A similar methodology was also used by Martinez et al. [55]. Common practice is to take the flow measurements in the position the turbine would be. Flow conditions should be the exact same as the turbine will be subjected to, although, in practice, this may not be possible. Novel adaptions of velocity measurement methods allow for velocities to be captured at multiple location along a beam, which allows for increased density of the conducted measurements by reducing the effort needed in the future [56].

In addition, according to Blackmore et al. [57], the order in which the flow velocity signals are averaged has an impact on the performance coefficients of the turbine. Squaring or cubing of the signals should be performed prior to any temporal and/or spatial averaging to avoid over-prediction of the coefficients.

If flow measurements are to be taken upstream of the turbine while the turbine is being tested, there should be a distance of a minimum of three diameters (3D) between the instrument and the rotor to avoid the turbine induction zone [58,59], where the flow slows down closer to the rotor.

\subsubsection{Testing of Floating Offshore Wind Turbines}

At present, there is limited guidance on laboratory testing of FOWTs and no published guidance that deals with the quantification of uncertainty or the variance between facilities. Much of the existing literature is derived from the oil and gas industry and published by the ITTC in the 7.5-02-07-03 series that deals with ocean engineering ${ }^{3}$. The ITTC guidelines are relatively high-level and do not provide standardised procedures for laboratory testing or detailed guidance on different aspects of FOWT testing. Addressing this gap will be a key outcome of the round robin testing that is part of MaRINET2. MaRINET2 deliverables D2.5, D2.6, and D4.3 $[15,20,60]$ will provide comprehensive guidelines on the tank and field testing process for FOWTs and other MRE devices when published later in 2021.

Laboratory testing of FOWTs examines global systems where both aerodynamics and hydrodynamics are considered. This creates conflicting scaling regimes, whereby Reynolds scaling applies to the wind emulation and Froude scaling to the wave action. Recently, guidance for testing FOWTs in this mixed regime was published by the H2020 LIFES50+ project [29]. This document recommends following a DNV style certification process, whereby the model tests are performed in real time under realistic forcing (irregular waves with turbulent wind). The recommended approach is to undertake a two-step process moving from wind tunnel to wave basin. The aerodynamics are initially validated in a physical wind test and replicated numerically using hardware in the loop in the hydrodynamic testing by means of multiple actuators. Ref. [61] has recently undertaken this method of hybrid testing. Utilising a multi-propeller device, a validation metric was developed to quantify the accuracy of testing against a set of tolerances. The concept of 
such a metric could help standardise and quantify testing accuracy across different test campaigns and test facilities.

\subsection{Materials}

Guidance is available for the testing of materials, including for use in the marine environment, through the shipbuilding and oil and gas industries [62]. However, this does not necessarily reflect the specific application(s) and/or environmental conditions required for MRE technologies, noting again the caveat in IEC-TS 62600-2 quoted at the end of Section 2.2. As with other topics, additional guidance will be developed as the MRE sector matures.

Specific gaps raised in terms of materials testing include the description of failure mechanisms related to different corrosion types, which is not found in the current standards and guidance for MECs. There is also a lack of guidance on dealing with combinations of effects, e.g., composite ageing and fatigue, or wear with corrosion or fatigue.

Regarding accelerated ageing testing, there are several applicable standards for offshore coatings' ageing (NORSOK M-501 /ISO 20340) and discontinuous immersion assays (splash and tidal simulation) (ASTM G44-99(2013)), but many others are carried out according to user specifications without following clear guidance, and without knowledge of the acceleration factor. This gap can lead to overly conservative approaches.

\subsubsection{Health and Safety}

Additional guidance on the health and safety $(\mathrm{H} \& S)$ aspects of testing is seen as a somewhat or very significant gap by $40 \%$ of respondents, with device developers particularly rating this as very significant.

Overarching H\&S principals are applicable to the MRE sector, including both lab and field testing. These are covered by general H\&S guidance including ISO 45001 [63]. There is also a wealth of guidance on maritime health and safety, much of which will be directly applicable to most aspects of the MRE industry. Trade Body Renewable UK has published sector-specific H\&S guides including [64,65]. Additionally, facilities will have their own $\mathrm{H} \& \mathrm{~S}$ procedures, as specifically mentioned in one facility managers' response. However, the questionnaire results indicate there may still be a need for additional guidance and awareness of the available resources.

\subsubsection{Uncertainties}

Lastly, there is a need for uncertainty analysis to become part of a standardised testing process. Existing IEC standards for performance assessment list the uncertainty items to include in studies, but limited guidance is given regarding how these should be processed and presented. IEC TS 62600-200 [66] on power performance assessment for tidal energy refers to wind standards for uncertainty case studies, but no standardised process dedicated to tidal devices has been produced to date. Similarly, IEC TS 62600-100 [67] for wave power performance assessment does not provide any clear requirement on how the uncertainty results should be displayed in the outputs.

In general, specific guidance on the calculation and presentation of uncertainties is limited for MRE devices at mature TRLs. The IEC technical specification for wind turbine performance assessment 61400-12-1 [68] provides a proper uncertainty case study. Similar case studies, specifically applied to wave and tidal, especially for the resource uncertainties, would be helpful and would help to standardise the calculation process. This type of analysis has to be facilitated in a limited way through the MaRINET2 project in both round robin activities [69] and through the transnational access programme [70].

There is a very wide range of device concepts in MRE testing, with many facilities available to test them, staffed by personnel from diverse technical backgrounds. Therefore, different procedures can be applied at different facilities, particularly for more complex environmental conditions and test procedures. This introduces increased uncertainties and 
potential bias, which the round robin testing in MaRINET2 aims to quantify, as covered in Section 6.1.

\section{Results of Survey to Prioritise Gaps Identified in Guidance}

The survey to prioritise the identified gaps received a total of 35 valid responses. These were from 11 facility managers, 21 technology developers, 2 researchers and a consultant. The split between the respondent types and programmes in which they participated is shown in Figure 1. For the technology developers, Figure 2 shows the types of technology and approximate TRL, which covers a range from TRL3 to TRL7. Note that two respondents are developing both wave and tidal technology, and one a wind/wave component/subsystem. Although almost a third of the responses are from facility managers, the majority of respondents are developing some form of tidal or (predominantly) wave technology. This might be a reflection of the participants in the programmes polled, but could also be linked to the earlier development stage of the wave sector.

As can be seen from Figure 3, many respondents agreed with the identified gaps. There was a large proportion of 'Don't know/No answer'; presumably because this is a wide-ranging set of topics, of which most people will only know a subset. Indeed, some of the respondents explicitly noted that they did not feel qualified to judge certain areas.

The responses received, both rankings and textual comments, have been used to inform the analysis in Section 4.

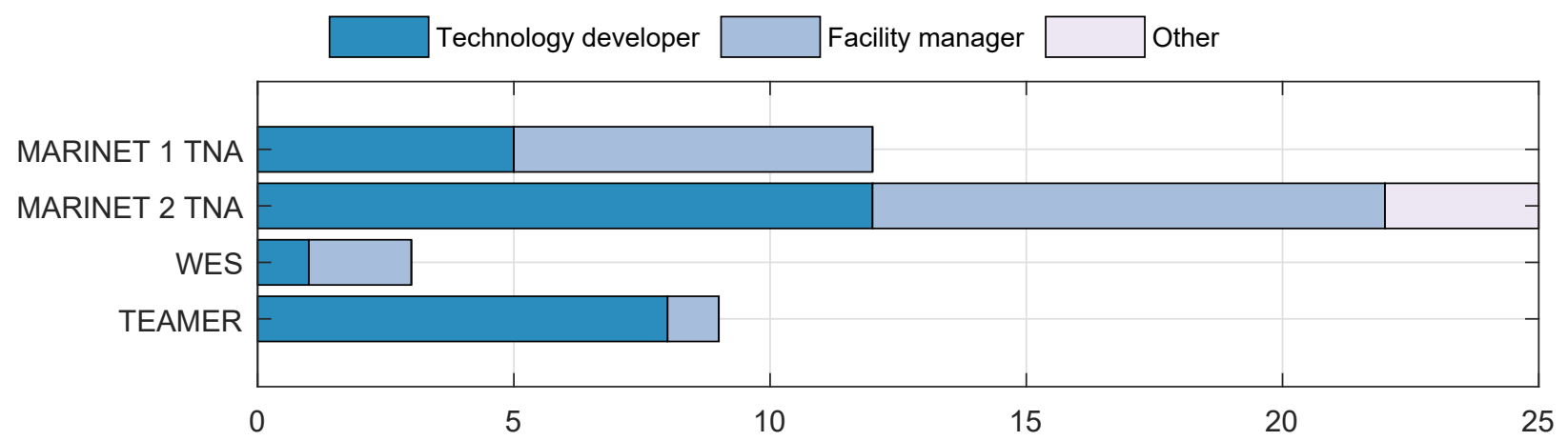

Figure 1. Breakdown of respondents by type and programme(s) they have participated in.

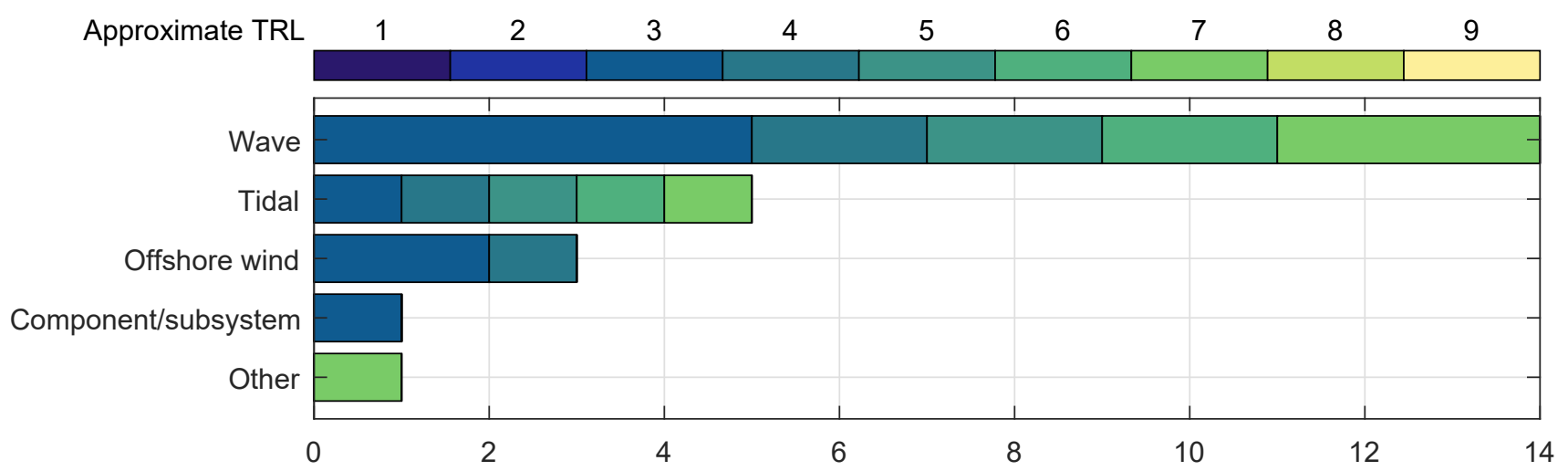

Figure 2. Breakdown of technology developer responses by technology(s) and approximate TRL. 


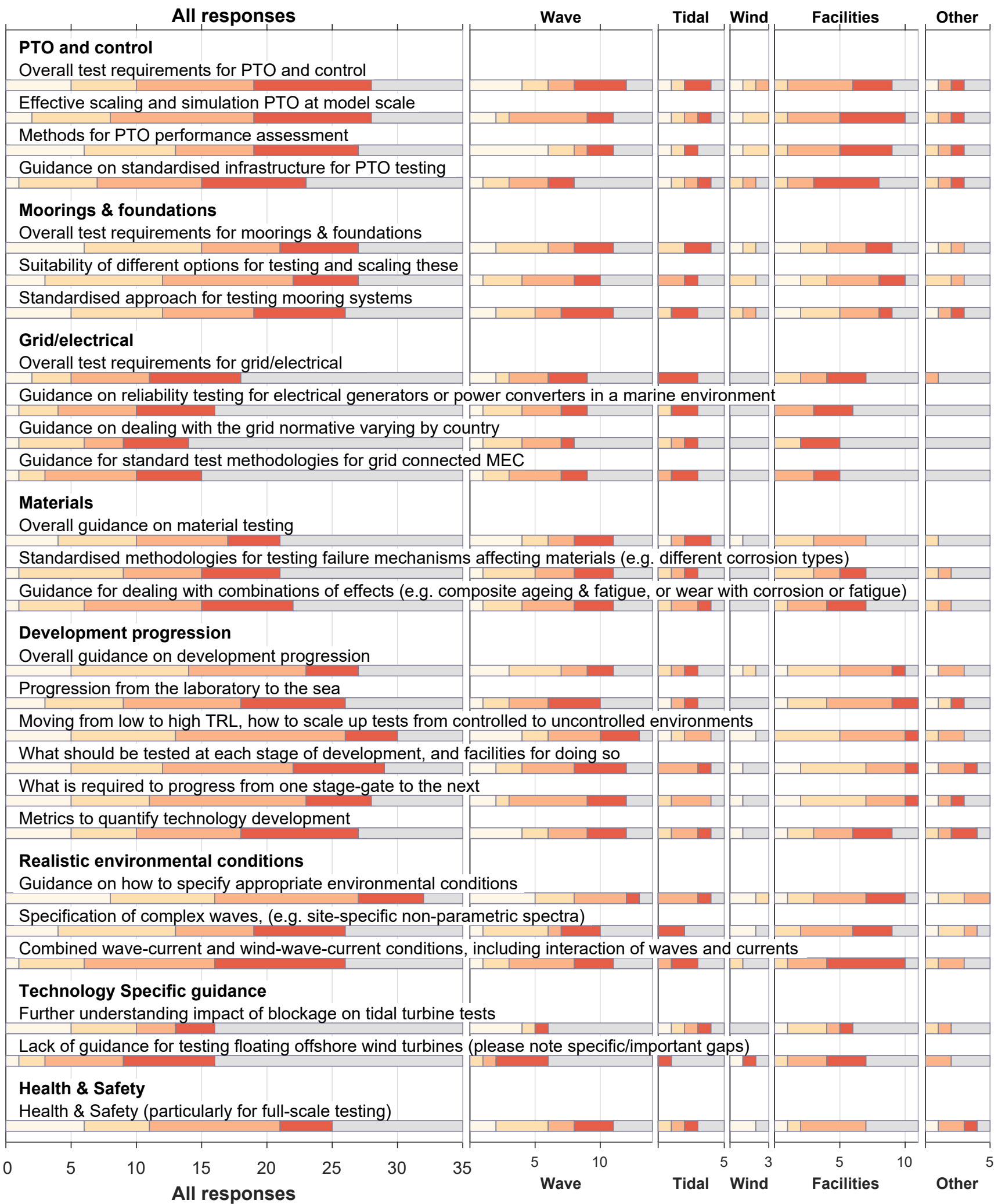

Figure 3. Responses ranking how significant each gap in published guidance is perceived to be. Leftmost panel shows all responses; other panels show these responses split by wave/tidal/offshore wind technology developers, test facility managers, and others. X-scales equal between all panels. 


\section{Pathway to Standardised Approach for MRE Testing}

This section outlines some of the actions being undertaken, in the MaRINET2 project and elsewhere, to develop and promote a standardised approach for the testing of MRE devices and components.

\subsection{MaRINET2 Round Robin}

\subsubsection{Objectives}

The MaRINET2 round robin (RR) series of testing has been designed to identify the effects individual laboratory facilities (wave tanks, structural rigs etc) have on performance results. The programme tests generic technologies (wind, wave, tidal and crosscutting components) under the same test conditions in a variety of facilities. The analysis between facilities considers all sources of variance from experimental setup, dimensional disparity, instrumentation, and post processing methodology. The ultimate aim of the round robin programme is to provide an understanding on the causes of variation between facilities in order to develop a standardised approach to ORE laboratory testing.

\subsubsection{Testing Procedure and Preliminary Findings}

The RR programme has been customised by technology type to focus on previously unquantified sources of variance between facilities. The tidal energy system testing focuses on the effect of combined wave-current interaction on the turbine, with a 3-bladed horizontal axis turbine tested at the wave and current circulating tank of Ifremer, the wave towing tank at CNR-INM, and the FloWave ocean energy research facility. The results show differences in the wave and current characteristics between facilities which, ultimately, have an impact on the turbine loading and performance. For example, a 10\% difference in the flow velocity between facilities can generate differences in the turbine performance coefficients of up to $25 \%$. A detailed analysis of the tests and facilities can be found in [53,71].

The wave RR testing featured two devices: a fixed oscillating water column (OWC) and a floating hinged raft. Preliminary analysis of both devices indicates that differences in the wave conditions generated at different facilities can have a profound impact on the results. This includes the ability to achieve the target wave heights and the shape of the waves themselves. Furthermore, different facilities have a variety of preferred methodologies for choosing the analysis interval, i.e., the time interval within the recorded data during which the device performance is determined, to account for the basin characteristics (e.g., the impact of reflections). Existing guidance [13] does not provide clear instructions on how the analysis interval should be selected, and how waves should be calibrated so that the target wave heights are achieved during the selected interval. The analysis methodology is also dependent on the analysis interval; for example, if the analysis interval is relatively short, to avoid the impact of reflections, then, for longer period waves, there may be only be a very small number of waves that can be analysed, which makes commonly used analysis methods such as Fourier transforms unsuitable, meaning that alternatives must be found. These issues are discussed in detail in $[69,72]$.

The wind RR features a generic semi-submersible horizontal axis floating wind turbine and, like the wave RR, aims to quantify the impact of the facility itself as well as the methodologies employed on the device response. The wind RR also aims to quantify the impact of different wind emulation methodologies and develop recommendations and guidelines for conducting a tank testing campaign on a floating wind device.

The RR programme on mooring testing [73] found that ISO guidance on moorings [74] is suitable for ORE testing, with a recommendation that higher-frequency loading be incorporated.

The findings and recommendations resulting from all aspects of round robin testing conducted in MaRINET2 will be published in D2.5 Round robin findings and recommendations in late 2021 [60]. 


\subsection{Development and Adoption of Standards}

It is evident that a wide variety of guidance applicable to marine renewable energy development has been produced over the last decade, with a summary provided in Appendix A. However, gaps in the standardised practise in testing still persist. Identifying gaps, as was undertaken in this manuscript, is only the first step in realising a standardised approach in the industry. Providing recommendations on how to close these gaps, such as those in Section 4, as well as consulting with the stakeholders to validate these, as demonstrated in Section 5, are further steps along the pathway to improved standards and guidance.

The next step is to ensure this information is incorporated into technical specifications and, eventually, standards. This can be achieved by engaging with technical committees, e.g., TC114, who are responsible for the IEC 62600 standards. The IEC standards are reviewed and updated through maintenance teams typically comprised of National Committee members. The period between revisions can vary from several years to decades depending on the maturity of the relevant industry to which the standard refers. The date at which standards are due for review is known as the Stability Date; for the IEC 62600 series, this ranges from end 2021 to 2024. It is within these windows that engagement with National Committees on the gaps should be undertaken, through direct participation, engagement with National Committee members, presentation of results at conferences, and publication of academic articles.

To incorporate recommendations for ITTC, the approach is different. The ITTC holds an triennial conference, whereby changes to their guidance can be approved by the executive committee. However, between conferences, specific technical committees such as the Specialist Committee on Hydrodynamic Modelling of Marine Renewable Energy Devices must meet at least four times. It is within these meetings that recommendations and terms of reference are set for the forthcoming conferences. To have the recommendations identified herein considered, liaison with this committee is recommended. The committee's presentation for the 29th ITTC in June 2021 includes reference to MaRINET2 bench marking through the round robin programme.

The program of testing activities undertaken within the MaRINET2 project and reported in this Special Issue is to test the robustness of new practices/procedures for their applicability in informing the development, rolling out, and accrediting future Practices and Standards. This is particularly timely given the ongoing roll-out of IEC technical specifications (IEC 62600 series) from Technical Committee TC114 Marine energy-wave, tidal and other water current converters.This process feeds directly in certification through the IEC system for certification to standards relating to equipment for use in Renewable Energy applications (IECRE). This essentially allows for renewable energy test laboratories (RETL) and renewable energy certification bodies (RECB) to apply these standards and specifications under a conformity assessment scheme. The end result is these RETLs and RECBs having the ability to issue conformity statements and test reports against IEC documents, aiding the industry in moving to a more mature position for a wide-scale deployment.

The gaps identified by the research programmes presented in this paper should lead to an update of the existing marine energy standards. The constant improvement of standards and guidelines are necessary in the MRE industry, which is in constant evolution. Even though documentation of related, more mature industries can be applied to some extent, the recent technology development projects have outlined the fact that a dedicated set of best practices for MRE devices testing and handling is also necessary.

\section{Conclusions}

There is already a wealth of guidance available on testing of MRE concepts. These cover many of the diverse topics within this multidisciplinary industry, as summarised in Appendix A and Noble et al. [1]. The gap analysis and industry survey show, however, that there is still a need for additional guidance on a range of specific points. These include 
how to test subsystems such as the PTO and control systems, plus how to model and test moorings and foundations. Integration of MECs with the electrical grid varies by country, so additional guidance on how to both accomplish and test this is required. General guidance is available for materials testing, but this does not fully address the specific applications required for marine energy. The development progression from concept to commercialisation is covered by several guidance documents, but perhaps not in sufficient detail, as this was still perceived as a gap by many. The marine environment is complex, and simulating this sufficiently in tank testing is important, but this is another area where additional guidance is perceived to be required. For tank testing of tidal turbines, both the impact of blockage and characterisation of flow through the turbine rotor may not be sufficiently documented. As the most nascent technology, tank testing of floating offshore wind has limited guidance, but is perhaps the most complex. The MaRINET2 project is working to partially address this gap, with the guidelines for test applicants [15]. Lastly, there is perhaps a need for sector specific guidance, both on health and safety aspects, and on dealing with uncertainties. This would compliment the broad range of general guidance that is available.

The MaRINET2 project is also contributing to the pathway to a standardised approach to MRE testing. The round-robin programme seeks to understand the effects of individual laboratories on the test results, and makes recommendations to minimise these differences. Similarly, guidance for test applicants is being produced and will be available later in 2021. This and other ongoing work is being incorporated into Technical Specifications through the IEC TC114 and others, which will eventually become standards for the industry. Alongside this, the next round of ITTC Recommended Procedures and Guidelines are likely to include findings from the round-robin testing within MaRINET2. Additional modelling methods to cover all aspects of MRE devices development will be needed in the future. With increased testing in scale facilities and deployments in the open sea, test facilities and developers gather additional information to make these models more accurate.

Although the work is based on a comprehensive review of published guidance, the identified gaps are based on the opinions of the authors and responses to a limited questionnaire, and so are somewhat subjective and not exhaustive. In terms of scope, it focuses on early-mid-stage testing of devices and key components/subsystems. The development and testing of balance of plant items such as electrical cables, substations, etc., were not included in the scope.

Despite the acknowledged gaps in the standards, one benefit to ORE being a relatively young and evolving sector is that industry practise and academic research are closely aligned, unlike more established industries, where standard practises are established and research is focused on optimising and improving performance, profitability and or safety. Future research and academic endeavours should continue to develop, publicise, and agree on best practices for testing. The gaps identified in this work are areas for particular focus. The industry would benefit from a similar academic exercise after a period of 3-5 years to re-survey stakeholders and re-examine the status of gaps in guidance, etc., the management of which could be undertaken in close cooperation with the ITTC and IEC.

This paper aims to summarise the status of guidance for the testing of marine renewable energy technologies. Gaps in this body of guidance are identified and discussed, along with a pathway to resolve these in the future development and adoption of standards for the sector.

Author Contributions: Conceptualization, M.O.; methodology, D.R.N.; formal analysis, D.R.N.; writing—original draft preparation, D.R.N.; writing—review and editing, D.R.N., M.O., F.J., E.R., R.M., F.K., P.R.T., L.J., Y.C., R.G., T.A.D.D. and N.V.; visualization, D.R.N.; supervision, L.J.; funding acquisition, J.M. All authors have read and agreed to the published version of the manuscript.

Funding: This research was funded by European Union's Horizon 2020 research and innovation programme under grant agreement number 731084, project MaRINET2 (Marine Renewable Infrastructure Network for Enhancing Technologies 2). 
Institutional Review Board Statement: Not applicable.

Informed Consent Statement: Informed consent was obtained from all subjects involved in the study.

Data Availability Statement: Anonymised data that support the findings of this study are available on request from the corresponding author (D.R.N.).

Acknowledgments: The authors would like to thank those who contributed to the MaRINET2 report on which this paper builds, and those who responded to the questionnaire for their input.

Conflicts of Interest: The authors declare no conflict of interest. The funders had no role in the design of the study; in the collection, analyses, or interpretation of data; in the writing of the manuscript, or in the decision to publish the results.

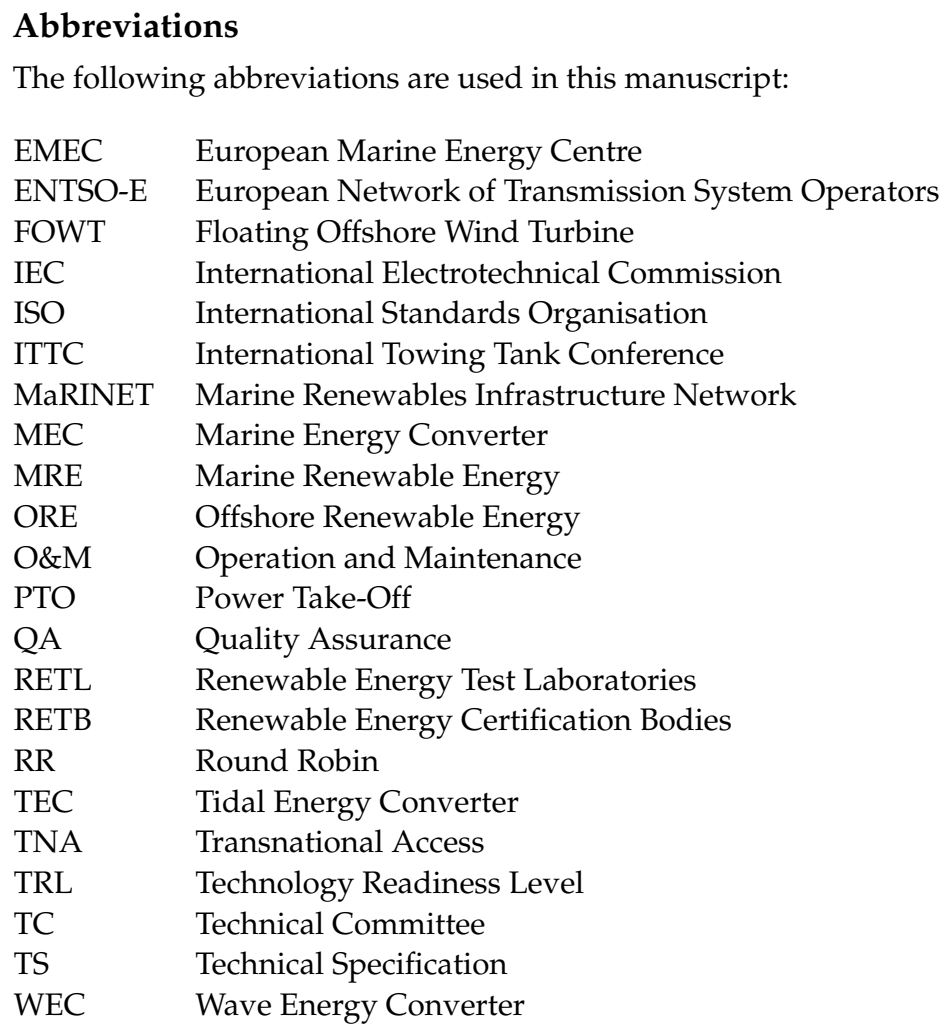

\section{Appendix A}

This appendix summarises the key topics covered in the 81 guidance documents reviewed under the MaRINET2 project relevant to testing of MRE devices. The topics considered are: the technology type(s) (wave, tidal, offshore wind); the type(s) of environmental conditions (wind, wave, current, and resource assessment); the type(s) of testing (lab, field, or covering specifics of the test facilities); general points on development progression, test programmes, scaling considerations, or scale models; typical subsystems and components (PTO/control, mooring/support structure, electrical/grid connection, component testing, or materials testing); and other points of measurement/instrumentation, data analysis/storage, numerical modelling, environmental/ecological aspects, and, lastly, relevant standards. These are collated in Table A1, with forecast publication dates for those still in preparation. Note that additional topics may be covered in the guidance documents in relation to aspects not relevant for testing, but this is excluded from the reported coverage. 
Table A1. Tabular summary of key topics covered by guidance documents. Symbols give an approximate level of detail and relevance for each topic: $\nabla$ briefly covered/partial relevance, $\diamond$ relevant/covered in detail, $\star$ covered in thorough detail.

International Electrotechnical Commission (IEC)—Standards and Technical Specifications (key documents only)

IEC TS 62600-2 Design requirements for marine energy sys- $2016 \quad \nabla \quad \nabla \quad \nabla \quad \diamond \diamond \nabla$
tems

IEC TS 62600-103: Guidelines for the early stage develop-

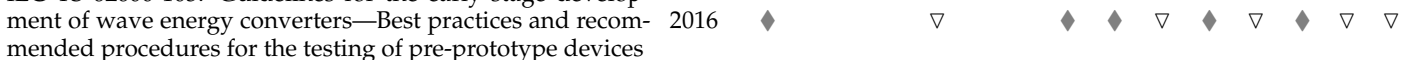

IEC TS 62600-202: Scale testing of tidal stream energy sys-

tems $^{+}$

International Towing Tank Conference (ITTC)—Recommended Procedures and Guidelines

(key documents only, for a full list see https://ittc.info/downloads/quality-systems-manual/recommended-procedures-and-guidelines/, accessed on 7 June 2021)

7.5-02-01-01 Guide to the Expression of Uncertainty in Ex- $2011 \quad \nabla \quad \nabla \quad \nabla$

perimental Hydrodynamics

7.5-02-07-01.1 Laboratory Modelling of Multidirectional Ir-

regular Wave Spectra

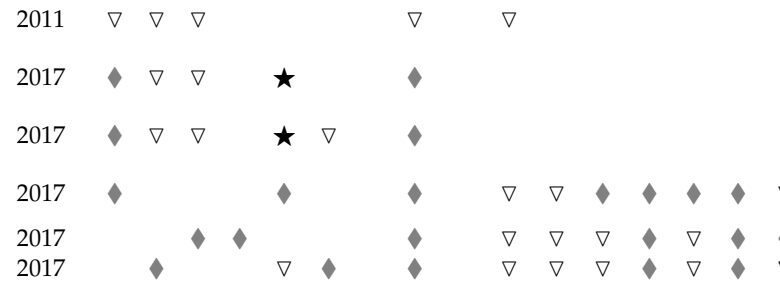

7.5-02-07-01.2 Laboratory Modelling of Waves: regular, irreg-

7.5-02-07-03.7 Wave Energy Converter, Model Test Experi-

ments

7.5-02-07-03.8 Model Tests for Offshore Wind Turbines

7.5-02-07-03.9 Model Tests for Current Turbines

2017

MaRINET2 Project Deliverables (Available at https://www.marinet2.eu/project-reports-2/, accessed on 7 June 2021)

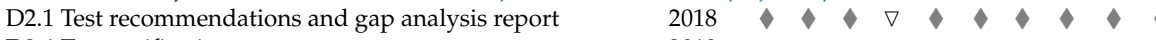

D2.4 Test verification process

D2.5 Round Robin findings and recommendations

D2.6 Final guidelines for test applicants ${ }^{\dagger}$

D2.7 Final guidelines for test facilities ${ }^{\dagger}$

D4.2 Report on remote access assessment and development

D4.3 MaRINET2 Standard Testing Procedures manual ${ }^{\dagger} \quad 2021$

D4.4 Present and future grid connection testing 2020

D6.4 MaRINET2 e-Infrastructure Pilot

2019
$2021^{+}$
$2021^{+}$
$2021^{+}$
2019
$2021^{+}$
2020
2019

MaRINET 1 Project Deliverables (Available at http://www.marinet2.eu/archive-reports-2/research-reports/, accessed on 7 June 2021)

D2.01 Wave Instrumentation Database

D2.02 Collation of Tidal Test Options

D2.03 Review of Relevant PTO Systems

D2.04 Collation of Offshore Wind-Wave Dynamics

D2.05 Report of Instrumentation Best Practice

D2.06 Report on Offshore Wind System Monitoring Practice

and Normalisation Procedures

D2.7 Tidal Measurement Best Practice Manual

D2.8 Best Practice Manual for Wave Simulation

D2.09 Standards for Wave Data Analysis, Archival \& Presen-

tation

D2.10 Best Practice Protocol for Offshore Wind System Fluid-

Structure Interaction Testing

D2.11 Best Practice Manual for PTO Testing

D2.12 Collation of Wave Simulation Methods

D2.13 Collation of Model Construction Methods

D2.14 Wave Data Presentation \& Storage Review

D2.16 Tidal Test Parameter Overview

D2.18 Tidal Data Analysis Best Practice

D2.19 Generation of a set of typical dynamic load regimes

for common conversion devices

D2.20 Report on Physical Modelling Methods for Floating

Wind Turbines

D2.21 Review of Mooring Testing Systems

D2.23 Review of Tow Tank Limitations

D2.25 Review Best Practice Standard for Electrical PTO Sys-

tems

D2.26 Collation of European grid codes

D2.28 Protocol for Model Construction

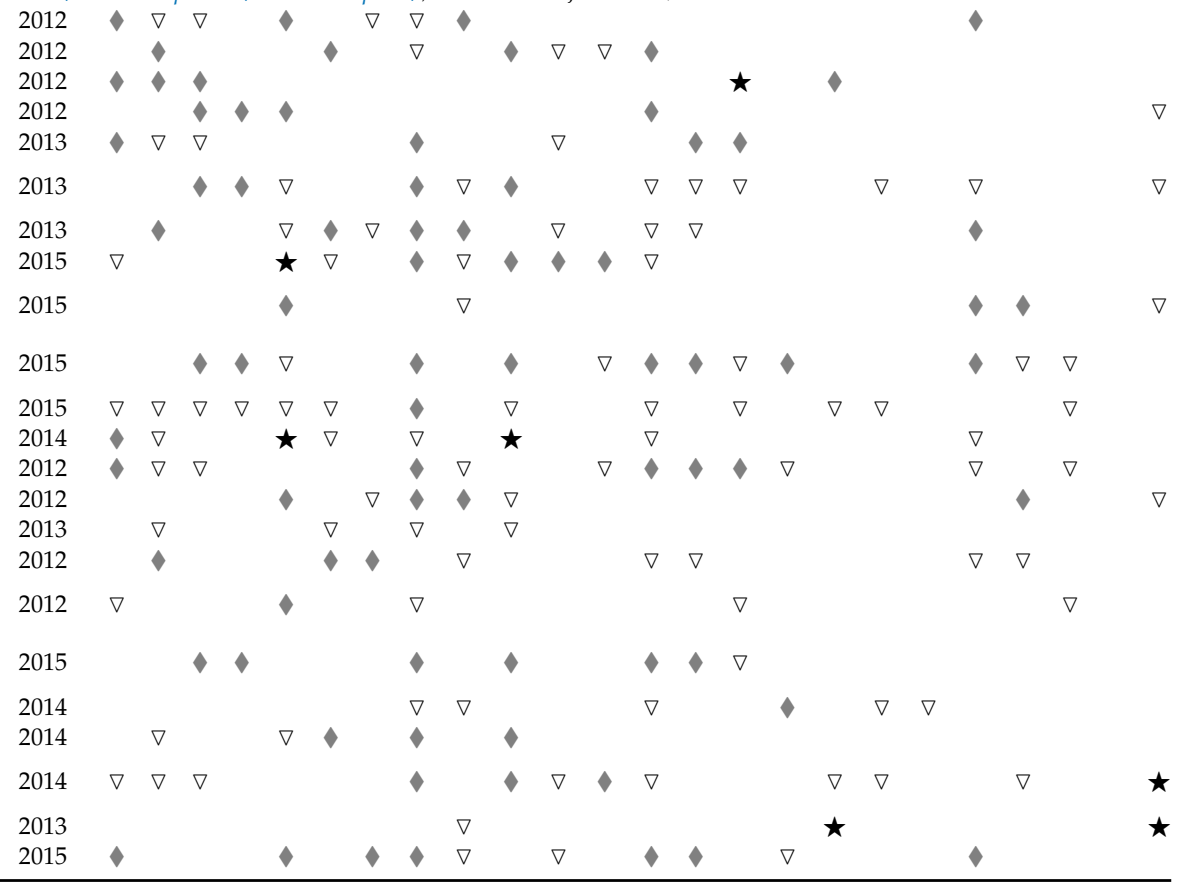


Table A1. Cont.

\begin{tabular}{|c|c|c|c|c|c|c|c|c|c|c|c|c|c|c|c|c|c|c|c|c|c|c|c|c|c|}
\hline Report Title & Date & 㟶 & 崖 & & 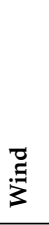 & $\stackrel{2}{3}$ & $\begin{array}{l}\vec{E} \\
\vec{\Xi} \\
\vec{U}\end{array}$ & & 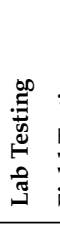 & 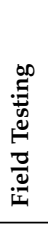 & 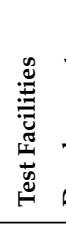 & 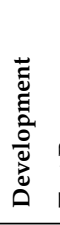 & 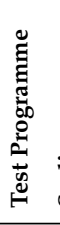 & 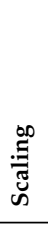 & 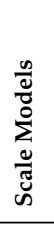 & 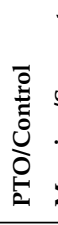 & 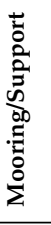 & 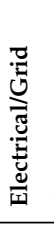 & 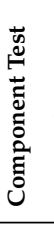 & 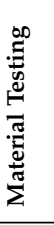 & 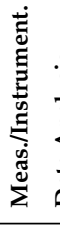 & 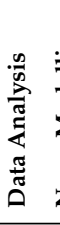 & 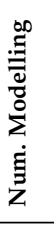 & 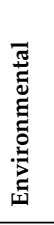 & \\
\hline D2.29 Report on Comparative Testing of Tidal Devices & 2015 & & $\diamond$ & & & & & & $\nabla$ & & $\nabla$ & & & $\nabla$ & & & & & & & $\nabla$ & & & & \\
\hline D4.01 Tank test related instrumentation \& best practice & 2014 & & & & $\bullet$ & $\bullet$ & & & $\bullet$ & & $\nabla$ & & & & $\bullet$ & & & & & & $\star$ & & & & \\
\hline D4.02 Report on dynamic test procedures & 2014 & $\nabla$ & $\nabla$ & $\nabla$ & $\nabla$ & $\nabla$ & $\nabla$ & $\nabla$ & $\bullet$ & & $\bullet$ & $\nabla$ & $\nabla$ & $\bullet$ & $\bullet$ & $\nabla$ & & $\bullet$ & & & & $\nabla$ & $\bullet$ & & \\
\hline D4.03 Report on grid integration \& power quality testing & 2014 & $\nabla$ & $\nabla$ & $\nabla$ & & & & & & & & & & & & & & $\nabla$ & & & & & & & \\
\hline D4.04 Report on low frequency response and moorings & 2014 & & & & & $\nabla$ & & & $\nabla$ & $\nabla$ & & & & & $\nabla$ & & $\star$ & & & & & & $\nabla$ & & \\
\hline D4.05 Report on non-intrusive wave field measurement & 2014 & & & & & $\diamond$ & & & $\nabla$ & $\nabla$ & & & & & & & & & & & $\star$ & & & & \\
\hline $\begin{array}{l}\text { D4.06 Data reports and data bases on coastal \& offshore } \\
\text { wind measurements }\end{array}$ & 2014 & & & $\nabla$ & $\bullet$ & & & $\nabla$ & & $\nabla$ & & & & & & & & & & & $\bullet$ & & & & \\
\hline $\begin{array}{l}\text { D4.07 Best Practice Report on Environmental Monitoring \& } \\
\text { New Study Techniques }\end{array}$ & 2014 & $\nabla$ & $\nabla$ & & & & & & & $\nabla$ & & & & & & & & & & & $\bullet$ & & & $\star$ & \\
\hline $\begin{array}{l}\text { D4.08 Database for environmental monitoring techniques \& } \\
\text { equipment }\end{array}$ & 2013 & & & & & & & & & $\nabla$ & & & & & & & & & & & $\nabla$ & & & $\bullet$ & \\
\hline D4.09 Report on remote underwater motion measurement & 2015 & & & & & & & & $\nabla$ & $\bullet$ & $\bullet$ & & & & & & & & & & $\bullet$ & & & $\nabla$ & \\
\hline D4.10 Report on Real Time Estin & 2015 & $\nabla$ & & & & $\bullet$ & & & & $\nabla$ & & & & & & $\bullet$ & & & & & & & & & \\
\hline $\begin{array}{l}\text { D4.11 Report on new instrumentation and field measuring } \\
\text { technology for tidal currents }\end{array}$ & 2015 & & $\nabla$ & & & & $\bullet$ & & $\nabla$ & $\bullet$ & $\nabla$ & & & & & & & & & & $\bullet$ & $\nabla$ & & & \\
\hline $\begin{array}{l}\text { D4.12 Report on design and accuracy of the sensor and SHM- } \\
\text { system }\end{array}$ & 2015 & & & $\nabla$ & & & & & $\bullet$ & & $\nabla$ & & & & $\bullet$ & & $\bullet$ & & & $\nabla$ & $\bullet$ & $\nabla$ & & & \\
\hline D4.13 Report on field test buoy research & 2015 & & & & & $\nabla$ & $\nabla$ & & & $\nabla$ & $\nabla$ & & & & & & - & & & & - & & & & \\
\hline D4.14 Report on & 2014 & & & & & & & & & & & & & & & & & $\star$ & & & & & & & \\
\hline D4.15 Report on numerical methods for PTO systems & 2014 & $\nabla$ & $\nabla$ & & & & & & & & $\nabla$ & & & $\bullet$ & $\bullet$ & $\nabla$ & & $\nabla$ & $\nabla$ & & & & $\star$ & & \\
\hline $\begin{array}{l}\text { D4.16 Report on options for full-scale wind resource survey- } \\
\text { ing }\end{array}$ & 2014 & & & & $\nabla$ & & & $\nabla$ & & $\nabla$ & & & & & & & & & & & $\nabla$ & & & & \\
\hline D4.17 Report on environmental monitoring protocols & 2014 & & & & & & & & & $\nabla$ & & & & & & & & & & & $\nabla$ & & & $\star$ & 5 \\
\hline \multicolumn{26}{|l|}{$\begin{array}{l}\text { Equimar Project Deliverables } \\
\text { (deliverables relevant to testing }\end{array}$} \\
\hline $\begin{array}{l}\text { D1.1 Global analysis of pre-normative research activities for } \\
\text { marine energy }\end{array}$ & 2009 & $\nabla$ & $\nabla$ & & & $\nabla$ & $\nabla$ & $\nabla$ & $\nabla$ & $\nabla$ & & $\nabla$ & & & & & & & & & & & & $\nabla$ & \\
\hline D1.2 Recommendations from other sectors & 2009 & & & & & & & & & & & & & & & $\nabla$ & $\nabla$ & $\nabla$ & & $\nabla$ & $\nabla$ & $\nabla$ & & $\nabla$ & \\
\hline D2.2 V & 2011 & & & & & $\star$ & $\nabla$ & - & & & & & & & & & & & & & 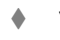 & $\nabla$ & & & \\
\hline D2.3 Applic & 2010 & & & & & $\bullet$ & $\nabla$ & 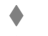 & & & & & & & & & & & & & & & $\star$ & & \\
\hline D2.4 V & 2011 & & & & & $\nabla$ & & $\bullet$ & & & & & & & & & & & & & & & - & & \\
\hline apolation & 2011 & & & & & $\nabla$ & & $\bullet$ & & & & & & & & & & & & & & $\nabla$ & & & \\
\hline D2.7 Re & 2010 & & & & & $\nabla$ & $\nabla$ & $\bullet$ & & & & $\nabla$ & & & & & & & & & & $\nabla$ & $\nabla$ & & \\
\hline $\begin{array}{l}\text { D3.1 Identification of Lin } \\
\text { Adopted for Early Stage Ti }\end{array}$ & 2009 & $\nabla$ & $\nabla$ & & & & & & $\nabla$ & $\nabla$ & & $\nabla$ & & & & $\nabla$ & $\nabla$ & & & & & & $\nabla$ & & \\
\hline $\begin{array}{l}\text { D3.2 Concept Appraisal and Tank Testing Practices for 1st } \\
\text { Stage Prototype Devices }\end{array}$ & 2009 & & $\nabla$ & & & & & & $\nabla$ & $\nabla$ & & & $\nabla$ & & & $\nabla$ & & & $\nabla$ & & & & & & \\
\hline $\begin{array}{l}\text { D3.3 Assessment of current practice for tank testing of small } \\
\text { marine energy devices }\end{array}$ & 2010 & $\nabla$ & $\nabla$ & & & $\nabla$ & $\nabla$ & & $\bullet$ & & $\nabla$ & & & $\nabla$ & $\nabla$ & & & & & & $\bullet$ & $\nabla$ & & & \\
\hline $\begin{array}{l}\text { D3.4 Best practice for tank testing of small marine energy } \\
\text { devices }\end{array}$ & 2010 & $\nabla$ & $\nabla$ & & & & & & $\bullet$ & & & & $\nabla$ & & & & & & & & & $\bullet$ & & & \\
\hline D4.2 Data Analysis \& Presentation To Quantify Uncertainty & 2010 & $\nabla$ & $\nabla$ & & $\nabla$ & $\nabla$ & $\nabla$ & $\nabla$ & & & & & & & & $\nabla$ & & $\nabla$ & & & & $\nabla$ & & & \\
\hline D4.3 Test $\mathrm{Si}$ & 2011 & $\nabla$ & $\nabla$ & & & $\nabla$ & $\nabla$ & $\nabla$ & & $\nabla$ & $\star$ & & & & & & & & & & & & & & \\
\hline $\begin{array}{l}\text { D5.1 Guidance protocols on choosing of electrical connec- } \\
\text { tion configurations }\end{array}$ & 2009 & & & & & & & & & $\nabla$ & $\nabla$ & & & & & & & $\star$ & & & & & & & \\
\hline D5.2 Device classification template & 2010 & $\bullet$ & $\bullet$ & & & & & & & & & & & & & • & $\bullet$ & & & & & & & & \\
\hline $\begin{array}{l}\text { D5.3 Protocols and guidance for device specification and } \\
\text { quantification of performance }\end{array}$ & 2010 & $\nabla$ & $\nabla$ & & & $\nabla$ & $\nabla$ & $\nabla$ & & & & & & & & & & & & & & & & & \\
\hline \multicolumn{26}{|c|}{$\begin{array}{l}\text { European Marine Energy Centre (EMEC) draft standards and guides for wave and tidal energy. } \\
\text { (see http://wwww.emec.org.uk/standards/, accessed on } 7 \text { June 2021) Six of these were submitted for IEC TC 114, marked*. }\end{array}$} \\
\hline $\begin{array}{l}\text { 1. Assessment of Performance of Wave Energy Conversion } \\
\text { Systems* }\end{array}$ & 2009 & $\nabla$ & & & & $\bullet$ & $\nabla$ & $\nabla$ & & $\bullet$ & & & & & & & & & & & $\bullet$ & & & & \\
\hline $\begin{array}{l}\text { 2. Assessment of Performance of Tidal Energy Conversion } \\
\text { Systems* }\end{array}$ & 2009 & & $\nabla$ & & & $\nabla$ & $\bullet$ & $\nabla$ & & $\bullet$ & & & & & & & & & & & $\nabla$ & $\bullet$ & & & \\
\hline 3. Assessment of Wave Energy Resource * & 2009 & & & & & $\bullet$ & & $\star$ & & & & & & & & & & & & & $\bullet$ & $\bullet$ & $\bullet$ & & \\
\hline 4. Assessment of Tidal Energy Resource * & 2009 & & & & & & - & $\star$ & & & & & & & & & & & & & - & - & - & & \\
\hline $\begin{array}{l}\text { 5. Guidelines for Health \& Safety in the Marine Energy In- } \\
\text { dustry }\end{array}$ & 2009 & $\nabla$ & $\nabla$ & & & & & & & $\nabla$ & & & & & & & & & & & & & & & \\
\hline 6. Guidelines for Marine Energy Certification Schemes * & 2009 & $\nabla$ & $\nabla$ & & & & & & & & & & & & & & & & & & & & & & \\
\hline $\begin{array}{l}\text { 7. Guidelines for Design Basis of Marine Energy Conversion } \\
\text { Systems* }\end{array}$ & 2009 & $\nabla$ & $\nabla$ & & $\nabla$ & $\nabla$ & $\nabla$ & & & & & & & & & & $\nabla$ & $\nabla$ & $\nabla$ & $\nabla$ & & & & $\nabla$ & \\
\hline
\end{tabular}


Table A1. Cont.

\begin{tabular}{|c|c|c|c|c|c|c|c|c|c|c|c|c|c|c|c|c|c|c|c|c|c|c|c|c|}
\hline Report Title & Date & 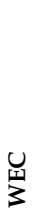 & U & 3 & 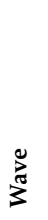 & $\begin{array}{l}\vec{E} \\
\stackrel{\Xi}{\Xi}\end{array}$ & 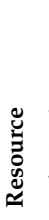 & 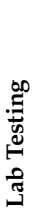 & 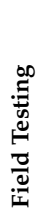 & 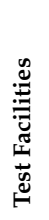 & 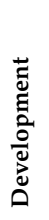 & 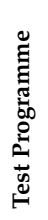 & $\underset{\tilde{J}}{: 00}$ & 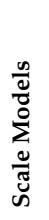 & 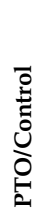 & 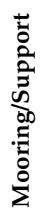 & 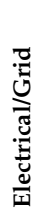 & 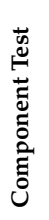 & 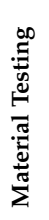 & 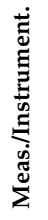 & $\begin{array}{l}\frac{n}{n} \\
\frac{2}{\pi} \\
\frac{\pi}{2} \\
\frac{\pi}{\pi} \\
0\end{array}$ & 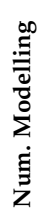 & 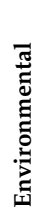 & 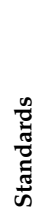 \\
\hline $\begin{array}{l}\text { 8. Guidelines for Reliability, Maintainability and Survivabil- } \\
\text { ity of Marine Energy Conversion Systems }\end{array}$ & 2009 & $\nabla$ & $\nabla$ & & & & & & & & & & & & & & & & & & & & & \\
\hline $\begin{array}{l}\text { 9. Guidelines for Grid Connection of Marine Energy Conver- } \\
\text { sion Systems }\end{array}$ & 2009 & & & & & & & & & & & & & & & & $\star$ & & & & & & & $\bullet$ \\
\hline 10. Tank Testing of Wave Energy Conversion Systems & 2009 & $\nabla$ & & & $\diamond$ & & & $\bullet$ & $\bullet$ & $\nabla$ & $\nabla$ & $\nabla$ & $\nabla$ & $\nabla$ & $\nabla$ & & & & & $\bullet$ & $\nabla$ & & & \\
\hline $\begin{array}{l}\text { 11. Guidelines for Project Development in the Marine En- } \\
\text { ergy Industry }\end{array}$ & 2009 & $\bullet$ & $\bullet$ & & & & $\nabla$ & & & & & & & & & & & & & & & & $\nabla$ & \\
\hline $\begin{array}{l}\text { 12. Guidelines for Manufacturing, Assembly and Testing of } \\
\text { Marine Energy Conversion Systems }\end{array}$ & 2009 & & & & & & & & & & & & & & & & & & $\nabla$ & & & & & \\
\hline \multicolumn{25}{|l|}{ Other guidance } \\
\hline $\begin{array}{l}\text { UEDIN Best Practice Guidelines for Tank Testing of Wave } \\
\text { Energy Converters }\end{array}$ & 2010 & $\nabla$ & & & $\nabla$ & & & $\bullet$ & & & & & $\nabla$ & $\nabla$ & & & & & & $\nabla$ & & $\nabla$ & & \\
\hline $\begin{array}{l}\text { OES-IA Guidelines for the development \& testing of wave } \\
\text { energy systems }\end{array}$ & 2010 & $\bullet$ & & & $\downarrow$ & & & $\diamond$ & $\downarrow$ & $\nabla$ & $\star$ & 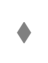 & & & & & & & & $\bullet$ & & & & \\
\hline $\begin{array}{l}\text { SuperGen Marine Guidance for Numerical Modelling in } \\
\text { Wave and Tidal Energy }\end{array}$ & 2010 & $\nabla$ & $\nabla$ & & & & & & & & & & $\nabla$ & & & & & & & & & $\diamond$ & & \\
\hline
\end{tabular}

${ }^{\dagger}$ Manuscript in preparation, forecast publication dates. ${ }^{*}$ EMEC draft standards submitted for IEC TC 114.

\section{Notes}

Wave Energy Scotland programmes https:/ / www.waveenergyscotland.co.uk/programmes/, accessed on 14 June 2021.

Testing Expertise and Access for Marine Energy Research https:/ / teamer-us.org/, accessed on 4 March 2021.

Register of ITTC guidelines available at https:/ / www.ittc.info/downloads / quality-systems-manual/recommended-proceduresand-guidelines/, accessed on 6 July 2021.

\section{References}

1. Noble, D.R.; Draycott, S.; Ordonez Sanchez, S.; Porter, K.; Johnstone, C.; Finch, S.; Judge, F.; Desmond, C.; Santos Varela, B.; Mendia, J.L.; et al. D2.1 Test Recommendations and Gap Analysis Report. Technical Report. MaRINET2 Consortium, 2018. Available online: https: / / www.marinet2.eu/project-reports-2/ (accessed on 7 June 2021).

2. Hodges, J.; Henderson, J.; Ruedy, L.; Soede, M.; Weber, J.; Ruiz-Minguela, P.; Jeffrey, H.; Bannon, E.; Holland, M.; Maciver, R.; et al. An International Evaluation and Guidance Framework for Ocean Energy Technology; Technical Report; IEA-OES: Lisbon, Portugal, 2021. Available online: https:/ / www.ocean-energy-systems.org/publications/oes-documents/ (accessed on 4 March 2021).

3. ARENA. Commercial Readiness Index for Renewable Energy Sectors; Technical Report; Australian Renewable Energy Agency: Canberra, Australia, 2014. Available online: https:/ / arena.gov.au/assets/2014/02/Commercial-Readiness-Index.pdf (accessed on 9 August 2021).

4. Weber, J. WEC Technology Readiness and Performance Matrix-Finding the Best Research Technology Development Trajectory. In Proceedings of the International Conference on Ocean Energy, Dublin, Ireland, 17-19 October 2012.

5. Noble, D.R.; Draycott, S.; Davey, T.A.D.; Bruce, T. Testing marine renewable energy devices in an advanced multi-directional combined wave-current environment. In Proceedings of the ASME 36th International Conference on Ocean, Offshore and Arctic Engineering (OMAE2017), Trondheim, Norway, 25-30 June 2017; ASME: Trondheim, Norway, 2017; Volume 7B, p. V07BT06A020. [CrossRef]

6. Bahaj, A.S.; Blunden, L.; Anwar, A.A. Tidal-current Energy Device Development and Evaluation Protocol; Technical Report; University of Southampton: Southhampton, UK, 2008.

7. Holmes, B. Tank Testing of Wave Energy Conversion Systems; Technical Report; BSI: London, UK, 2009.

8. Holmes, B.; Nielsen, K. Guidelines for the Development and Testing of Wave Energy Systems; Technical Report; Hydraulics Maritime Research Centre, UCC: Cork, Ireland, 2010.

9. Driscoll, F.; Mauer, E.; Rieks, J. 2017 Marine Hydrokinetic Instrumentation Workshop Report, Technical Report NREL/TP5000-70591. Available online: https:/ / www.osti.gov/biblio/1425575-marine-hydrokinetic-instrumentation-workshop-report (accessed on 4 March 2021).

10. ORE Catapult; EMEC. Review of Standards/Guidelines for Marine Renewables (Wave E Tide); Technical Report July; ORE Catapult: Blyth, UK, 2014. Available online: https://tethys-engineering.pnnl.gov/sites/default/files/publications/ore2014.pdf (accessed on 22 May 2017).

11. IEC. TC 114 Marine Energy -Wave, Tidal and Other Water Current Converters. Available online: https:/ /www.iec.ch/dyn/ wWw /f?p=103:7:710392897852646::::FSP_ORG_ID,FSP_LANG_ID:1316,25 (accessed on 7 June 2021). 
12. Ingram, D.M.; Smith, G.H.; Bittencourt-Ferreira, C.; Smith, H.C.M. Protocols for the Equitable Assessment of Marine Energy Converters; Technical Report; EquiMar Consortium: Edinburgh, UK, 2011.

13. ITTC. Recommended Procedures and Guidelines: Analysis Procedure for Model Tests in Regular Waves 7.5-02-07-03.2; Procedure; ITTC: Zürich, Switzerland, 2017.

14. IEC. Marine Energy_Wave, Tidal and Other Water Current Converters_Part 2: Design Requirements for Marine Energy Systems; Technical Specification IEC TS 62600-2; International Electrotechnical Commission: Geneva, Switzerland, 2016.

15. Judge, F. D2.26 Final Guidelines for Test Applicants. Manuscript in Preparation. Technical Report. MaRINET2 Consortium, 2021. Available online: https:/ / www.marinet2.eu/project-reports-2/ (accessed on 7 June 2021).

16. Corlay, Y.; Vejayan, N.; le Boulluec, M.; Germain, G.; Martinez, R.; Ordonez, S.; Lopez, J.; Robles, E.; Candido, J.; Battensby, J.; et al. D2.7 Final Guidelines for Test Facilities. Technical Report. MaRINET2 Consortium, 2021. Available online: https: / / www.marinet2.eu/project-reports-2/ (accessed on 7 June 2021).

17. Griffiths, J.; Brooker, R. D2.4 Test Verification Process. Technical Report. MaRINET2 Consortium, 2019. Available online: https: / / www.marinet2.eu/project-reports-2/ (accessed on 7 June 2021).

18. Faÿ, F.X.; Robles, E.; Murray, D. D4.2 Report on Remote Access Assessment and Development. Technical Report. MaRINET2 Consortium, 2019. Available online: https:/ / www.marinet2.eu/project-reports-2/ (accessed on 7 June 2021).

19. Robles, E.; Nava, V.; Touzón, I.; Santos, M.; Murray, D.; Kelly, J.; Young, D.; Holdyk, A. D4.4: Present and Future Grid Connection Testing. Technical Report. MaRINET2 Consortium, 2020. Available online: https://www.marinet2.eu/project-reports-2/ (accessed on 7 June 2021).

20. Martinez, R.; Khalid, F.; O’Hana, J.; Le Boullec, M.; Salcedo Fernandez, F.; Robles Sestafe, E. MaRINET2—D4.3: Standard Testing Procedures. Technical Report. MaRINET2 Consortium, 2021. Available online: https://www.marinet2.eu/project-reports-2/ (accessed on 7 June 2021).

21. IEC. Marine Energy_Wave, Tidal and Other Water Current Converters_Part 1: Vocabulary; Technical Specification IEC TS 62600-1; International Electrotechnical Commission: Geneva, Switzerland, 2020.

22. IEC. Marine Energy - Wave, Tidal and Other Water Current Converters_Part 3: Measurement of Mechanical Loads; Technical Specification IEC TS 62600-3; International Electrotechnical Commission: Geneva, Switzerland, 2020.

23. IEC. Marine Energy_Wave, Tidal and Other Water Current Converters_Part 4: Specification for Establishing Qualification of New Technology; Technical Specification IEC TS 62600-4; International Electrotechnical Commission: Geneva, Switzerland, 2020.

24. IEC. Marine energy_Wave, Tidal and Other Water Current Converters_Part 30: Electrical Power Quality Requirements; Technical Specification IEC TS 62600-30; International Electrotechnical Commission: Geneva, Switzerland, 2018.

25. IEC. Marine Energy_Wave, Tidal and Other Water Current Converters_Part 103: Guidelines for the Early Stage Development of Wave Energy Converters: Best Practices and Recommended Procedures for the Testing of Pre-Prototype Scale Devices; Technical Specification IEC TS 62600-103; International Electrotechnical Commission: Geneva, Switzerland, 2018.

26. MET-CERTIFIED Development of International Standards and Certification Schemes for Marine Energy Technologies. Available online: http:/ / met-certified.eu/ (accessed on 9 June 2021).

27. Gujer, P.; Matthias, K. D7.1 Review of FOWT Guidelines and Design Practice. Technical Report. 2015. Available online: https:/ /lifes50plus.eu/results / (accessed on 9 June 2021).

28. IEC. Wind Energy Generation Systems_Part 3-2: Design Requirements for Floating Offshore Wind Turbines; Technical Specification IEC TS 61400-3-2; International Electrotechnical Commission: Geneva, Switzerland, 2019.

29. Thys, M.; Fontanella, A.; Taruffi, F.; Manjock, A.; Belloli, M. D7.9 Guidance and Recommended Methods for Hybrid/HIL-Based FOWT Experimental Testing. Technical Report. 2019. Available online: https:/ /lifes50plus.eu/results/ (accessed on 9 June 2021).

30. ITTC. Specialist Committee on Modelling of Environmental Conditions. Final Report and Recommendations to the 29th ITTC. In Proceedings of the 29th International Towing Tank Conference, Virtual. 13-18 June 2021.

31. ITTC. The Specialist Committee on Hydrodynamic Modelling of Marine Renewable Energy Devices. Final Report and Recommendations to the 29th ITTC. In Proceedings of the 29th International Towing Tank Conference, Virtual. $13-18$ June 2021.

32. Villate, J.; Ruiz-Minguela, P.; Berque, J.; Pirttimaa, L.; Cagney, D.; Cochrane, C.; Jeffrey, H. Strategic Research and Innovation Agenda for Ocean Energy; Technical Report; Ocean Energy Europe: Brussels, Belgium, 2020. Available online: https:/ / oceanenergy-europe. eu/wp-content/uploads/2020/05/ETIP-Ocean-SRIA.pdf (accessed on 28 October 2020).

33. IEC. Marine Energy-Wave, Tidal and Other Water Current Converters_Part 202: Scale Testing of Tidal Stream Energy Systems. Manuscript in Preparation; Draft Technical Specification; International Electrotechnical Commission: Geneva, Switzerland, 2020.

34. Draycott, S.; Sellar, B.G.; Davey, T.A.D.; Noble, D.R.; Venugopal, V.; Ingram, D.M. Capture and simulation of the ocean environment for offshore renewable energy. Renew. Sustain. Energy Rev. 2019, 104, 15-29. [CrossRef]

35. Draycott, S.; Davey, T.A.D.; Ingram, D.M.; Lawrence, J.; Day, A.H.; Johanning, L. Applying Site-Specific Resource Assessment: Emulation of Representative EMEC seas in the FloWave Facility. In Proceedings of the Twenty-Fifth International Ocean and Polar Engineering Conference (ISOPE2015), Big Island, HI, USA, 21-26 June 2015; pp. 815-821.

36. Venugopal, V.; Davey, T.A.D.; Smith, H.C.M.; Smith, G.H.; Holmes, B.; Barret, S.; Prevosto, M.; Maisondieu, C.; Cavaleri, L.; Bertotti, L.; et al. D2.2 Wave and Tidal Resource Characterisation. Technical Report. 2011. Available online: https://www. equimar.org/equimar-project-deliverables.html (accessed on 25 April 2014). 
37. Venugopal, V.; Davey, T.A.D.; Smith, H.; Smith, G.; Cavaleri, L.; Bertotti, L.; Lawrence, J. D2.3 Application of Numerical Models. Technical Report. 2010. Available online: https:/ /www.equimar.org/equimar-project-deliverables.html (accessed on 28 November 2016).

38. Draycott, S.; Noble, D.; Davey, T.A.D.; Bruce, T.; Ingram, D.; Johanning, L.; Smith, H.; Day, A.H.; Kaklis, P. Re-creation of site-specific multi-directional waves with non-collinear current. Ocean. Eng. 2017, 152, 391-403. [CrossRef]

39. Pillai, A.C.; Davey, T.; Draycott, S. A framework for processing wave buoy measurements in the presence of current. Appl. Ocean Res. 2021, 106, 102420. [CrossRef]

40. IEC. Marine energy_Wave, Tidal and Other Water Current Converters_Part 101: Wave Energy Resource Assessment and Characterization; Technical Specification IEC TS 62600-101; International Electrotechnical Commission: Geneva, Switzerland, 2005.

41. IEC. Marine energy_Wave, Tidal and Other Water Current Converters_Part 102: Wave Energy Converter Power Performance Assessment at a Second Location Using Measured Assessment Data; Technical Specification IEC TS 62600-102; International Electrotechnical Commission: Geneva, Switzerland, 2016.

42. IEC. Marine Energy_Wave, Tidal and Other Water Current Converters—Part 201: Tidal Energy Resource Assessment and Characterization; Technical Specification IEC TS 62600-201; International Electrotechnical Commission: Geneva, Switzerland, 2015.

43. IEC. Marine energy_Wave, Tidal and Other Water Current Converters_Part 10: The Assessment of Mooring System for Marine Energy Converters (MECS); Technical Specification IEC TS 62600-10; International Electrotechnical Commission: Geneva, Switzerland, 2015.

44. Ekström, R.; Leijon, M. Control of offshore marine substation for grid-connection of a wave power farm. Int. J. Mar. Energy 2014, 5, 24-37. [CrossRef]

45. Endegnanew, A.G.; D’Arco, S.; Torres-Olguin, R.E.; Marvik, J.I.; Tedeschi, E. D2.26 Collation of European Grid Codes. Technical Report. MaRINET, 2013. Available online: https:/ / www.marinet2.eu/archive-reports-2/research-reports/ (accessed on 1 September 2021).

46. Robles, E.; Haro-Larrode, M.; Santos-Mugica, M.; Etxegarai, A.; Tedeschi, E. Comparative analysis of European grid codes relevant to offshore renewable energy installations. Renew. Sustain. Energy Rev. 2019, 102, 171-185. [CrossRef]

47. IEC. Wind Turbines-Part 21: Measurement and Assessment of Power Quality Characteristics of Grid Connected Wind Turbines; International Standard IEC 61400-21; International Electrotechnical Commission: Geneva, Switzerland, 2008.

48. Harnois, V.; Weller, S.D.; Johanning, L.; Thies, P.R.; Le Boulluec, M.; Le Roux, D.; Soule, V.; Ohana, J. Numerical model validation for mooring systems: Method and application for wave energy converters. Renew. Energy 2015, 75, 869-887. [CrossRef]

49. Spearman, D.K.; Strivens, S. Floating Wind Joint Industry Project: Phase 2 Summary Report. Technical Report. 2020. Available online: https: / / www.carbontrust.com/resources/floating-wind-joint-industry-project-phase-2-summary-report (accessed on 1 September 2021).

50. Yang, S.H.; Ringsberg, J.W.; Johnson, E.; Hu, Z. Biofouling on mooring lines and power cables used in wave energy converter systems-Analysis of fatigue life and energy performance. Appl. Ocean Res. 2017, 65, 166-177. [CrossRef]

51. Khalid, F.; Arini, N.R.; Johanning, L. Deliverable D2.4: Recommendations for WEC Mooring Guidelines and Standards. Technical Report. OPERA Consortium, 2019. Available online: http:/ / opera-h2020.eu/ (accessed on 1 September 2021).

52. Gaurier, B.; Germain, G.; Facq, J.V.; Johnstone, C.M.; Grant, A.D.; Day, A.H.; Nixon, E.; Di Felice, F.; Costanzo, M. Tidal Energy "Round Robin" Tests Comparisons between towing tank and circulating tank results. Int. J. Mar. Energy 2015, 12, 87-109. [CrossRef]

53. Gaurier, B.; Ordonez-Sanchez, S.; Facq, J.V.; Germain, G.; Johnstone, C.; Martinez, R.; Salvatore, F.; Santic, I.; Davey, T.; Old, C.; et al. MaRINET2 Tidal Energy Round Robin Tests-Performance Comparison of a Horizontal Axis Turbine Subjected to Combined Wave and Current Conditions. J. Mar. Sci. Eng. 2020, 8, 463. [CrossRef]

54. Bahaj, A.S.; Molland, A.F.; Chaplin, J.R.; Batten, W.M.J. Power and thrust measurements of marine current turbines under various hydrodynamic flow conditions in a cavitation tunnel and a towing tank. Renew. Energy 2007, 32, 407-426. [CrossRef]

55. Martinez, R.; Payne, G.S.; Bruce, T. The effects of oblique waves and currents on the loadings and performance of tidal turbines. Ocean Eng. 2018, 164, 55-64. [CrossRef]

56. Jourdain de Thieulloy, M.; Dorward, M.; Old, C.; Gabl, R.; Davey, T.; Ingram, D.M.; Sellar, B.G. On the Use of a Single Beam Acoustic Current Profiler for Multi-Point Velocity Measurement in a Wave and Current Basin. Sensors 2020, 20, 3881. [CrossRef] [PubMed]

57. Blackmore, T.; Myers, L.E.; Bahaj, A.S. Effects of turbulence on tidal turbines: Implications to performance, blade loads, and condition monitoring. Int. J. Mar. Energy 2016, 14, 1-26. [CrossRef]

58. Medici, D.; Ivanell, S.; Dahlberg, J.; Alfredsson, P.H. The upstream fl ow of a wind turbine: Blockage effect. Wind Energy 2011, 14, 691-697. [CrossRef]

59. Simley, E.; Pao, L.Y.; Gebraad, P.; Churchfield, M. Investigation of the impact of the upstream induction zone on LIDAR measurement accuracy for wind turbine control applications using large-eddy simulation. J. Phys. Conf. Ser. 2014, $524,012003$. [CrossRef]

60. Judge, F. D2.5 Round Robin Findings and Recommendations. Manuscript in Preparation. Technical Report. MaRINET2 Consortium, 2021. Available online: https:/ / www.marinet2.eu/project-reports-2/ (accessed on 7 June 2021).

61. Otter, A.; Murphy, J.; Desmond, C. Emulating aerodynamic forces and moments for hybrid testing of floating wind turbine models. J. Phys. Conf. Ser. 2020, 1618, 032022. [CrossRef] 
62. Lloyd's Register. Rules for the Manufacture, Testing and Certification of Materials; Technical Report; Lloyd's Register Group: London, UK, 2020. Available online: https:/ / www.lr.org/en-gb/rules-for-the-manufacture-testing-and-certification-of-materials / (accessed on 8 June 2021).

63. ISO. ISO 45001 Occupational Health and Safety Management Systems-Requirements with Guidance for Use. International Standard. Available online: https:/ / www.iso.org/standard/63787.html (accessed on 1 September 2021).

64. RenewableUK. Offshore Wind and Marine Energy Health and Safety Guidelines. Technical Report. 2014. Available online: https:/ / www.renewableuk.com/page/HealthSafety (accessed on 8 June 2021).

65. RenewableUK. Wave and Tidal Health and Safety Guide: Principles and Practice. Technical Report. 2014. Available online: https: / / www.renewableuk.com/page/HealthSafety (accessed on 8 June 2021).

66. IEC. Marine Energy_Wave, Tidal and Other Water Current Converters_Part 200: Electricity Producing Tidal Energy ConvertersPower Performance Assessment; Technical Specification IEC TS 62600-200; International Electrotechnical Commission: Geneva, Switzerland, 2013.

67. IEC. Marine Energy_Wave, Tidal and Other Water Current Converters_Part 100: Electricity Producing Wave Energy ConvertersPower Performance Assessment; Technical Specification IEC TS 62600-100; International Electrotechnical Commission: Geneva, Switzerland, 2012.

68. IEC. Wind Energy Generation Systems - Part 12-1: Power Performance Measurements of Electricity Producing Wind Turbines; International Standard IEC 61400-12-1; International Electrotechnical Commission: Geneva, Switzerland, 2017.

69. Judge, F.M.; Lyden, E.; O'Shea, M.; Flannery, B.; Murphy, J. Uncertainty in Wave Basin Testing of a Fixed Oscillating Water Column Wave Energy Converter. ASCE-ASME J. Risk Uncertain. Eng. Syst. Part B 2021. [CrossRef]

70. Robertson, A.N.; Bachynski, E.E.; Gueydon, S.; Wendt, F.; Schünemann, P.; Jonkman, J. Assessment of experimental uncertainty for a floating wind semisubmersible under hydrodynamic loading. In Proceedings of the International Conference on Offshore Mechanics and Arctic Engineering, Madrid, Spain, 17-22 June 2018; American Society of Mechanical Engineers: New York, NY, USA, 2018; Volume 51319, p. V010T09A076.

71. Martinez, R.; Gaurier, B.; Ordonez-Sanchez, S.; Facq, J.V.; Germain, G.; Johnstone, C.; Salvatore, F.; Santic, I.; Davey, T.; Old, C.; et al. Tidal Energy Round Robin Tests: A comparison of flow measurements and turbine loading. J. Mar. Sci. Eng. 2021, 9 , 425. [CrossRef]

72. Ohana, J.; Gueydon, S.; Judge, F.; Haquin, S.; Weber, M.; Lyden, E.; Thiebaut, F.; O'Shea, M.; Murphy, J.; Davey, T.; et al. Round robin tests on a hinged raft wave energy converter. J. Mar. Sci. Eng. 2021, 9, 946.

73. Khalid, F.; Davies, P.; Halswell, P.; Lacotte, N.; Thies, P.R.; Johanning, L. Evaluating Mooring Line Test Procedures through the Application of a Round Robin Test Approach. J. Mar. Sci. Eng. 2020, 8, 436. [CrossRef]

74. ISO. Fibre Ropes for Offshore Stationkeeping_Part 2: Polyester; International Standard IEC 18692-2; International Organization for Standardization: Geneva, Switzerland, 2019. 